\title{
LA UNIÓN REPUBLICANA EN EL CORAZÓN DE LA MONARQUÍA. EL TRIUNFO ELECTORAL DE 1903
}

\section{THE REPUBLICAN UNION PARTY IN THE HEART OF THE MONARCHY. THE ELECTORAL VICTORY OF 1903}

\author{
Santiago de Miguel Salanova \\ Université Paris IV-Sorbonne
}

Recibido el 15/5/2015 y aceptado el 7-4-2016.

Resumen: Este trabajo analiza el triunfo republicano en las elecciones a Cortes de 1903 en Madrid mediante el análisis de los mecanismos de movilización y captación del voto utilizados por la candidatura del proyecto coalicionista de Unión Republicana. Se abordan en él claves contextuales que permiten explicar el éxito republicano, como los sucesos estudiantiles de Salamanca de abril de 1903 y el clima de conflictividad social alcanzado después en Madrid. Finalmente, se realiza un ejercicio de sociología electoral analizando el voto republicano a través de una perspectiva microhistórica. Para esta tarea se ha acudido a las actas electorales y a su cruzamiento con los datos del Padrón de Habitantes de Madrid de 1905, fuente documental básica para conocer el perfil socioprofesional de cada zona.

Palabras clave: Madrid, Unión Republicana, Elecciones generales, tendencias de voto.

\footnotetext{
Abstract: This work analyses the Republican victory in the 1903 general election in Madrid with particular emphasis on several issues. Firstly, the mobilization strategies applicated by the political party Unión Republicana. Secondly, the contextual clues that explain the Republican success, as student mobilization in Salamanca in April and the climate of social unrest reached in Madrid. Finally, an exercise in electoral sociology is done by measuring the Republican vote tendencies through a micro-historical perspective. For this task,
} 
tally sheets have been used, crossing them with data provided by the municipal register of inhabitants of 1905 , being this source essential to understand the socio-professional profile of each area in Madrid.

Key words: Madrid, Republican Union, General Elections, voting behaviour. 


\section{Introducción}

Las elecciones a Cortes de 26 de abril de 1903 representan un episodio clave de la etapa de la Restauración y su análisis se justifica por varias cuestiones. En primer lugar, porque se enmarcan dentro de un período de renovación de las élites políticas, con conservadores y liberales envueltos en divisiones internas respecto al problema de su jefatura política tras las muertes de Antonio Cánovas del Castillo y Práxedes Mateo Sagasta. En segundo término, porque tuvieron lugar durante el primer turno conservador representado por el gobierno de Francisco Silvela, etapa en la que Antonio Maura, ministro de Gobernación, puso en práctica su revolución desde arriba para dar mayor autenticidad al sistema político y superar la apatía de ciertos sectores sociales despertando sus responsabilidades cívicas ${ }^{1}$.

Si bien ese objetivo no culminaría hasta la ley electoral de 1907, tuvo una primera representación en el contexto previo a las elecciones de 1903. En un discurso pronunciado ante los gobernadores provinciales en diciembre de 1902, Maura aludió a la inminente contienda pidiéndoles que suspendieran a alcaldes, concejales y corporaciones que utilizaran la coacción y que reunieran información sobre «los desmanes electorales que se cometieran por toda clase de funcionarios» ${ }^{2}$. Dos meses después, ordenó que se facilitara a los notarios y testigos designados por los candidatos la asistencia de la fuerza pública y la de delegados gubernativos para «vigilar, formalizar actas o copias, no solo con relación a las operaciones electorales, sino también las faltas o delitos que se intentaren» ${ }^{3}$. Parecía ilusorio acabar con la corrupción electoral de forma tan abrupta, pero era evidente que Maura no estaba dispuesto a dar pábulo a elecciones simuladas. Por el contrario, parecía decidido a emprender una fiscalización reparadora del sistema.

La actitud de Maura es fundamental para explicar el éxito republicano en las elecciones celebradas en Valencia, Barcelona y Madrid ${ }^{4}$. Sin

\footnotetext{
1 María Jesús González, Antonio Maura. Biografía y proyecto de Estado, Biblioteca Nueva, Madrid, 2007.

2 José Ruiz Castillo, Antonio Maura. Treinta y cinco años de vida pública. Vol. I, Biblioteca Nueva, Madrid, 1917, pp. 271-272.

3 Gaceta de Madrid, 20 de febrero de 1903.

${ }_{4}$ Joan B. Culla, El republicanisme lerrouxista a Catalunya (1901-1923), Curial, Barcelona, 1986 y Luis Aguiló, Sociología electoral valenciana (1903-1923): (las elecciones en Valencia durante el reinado de Alfonso XIII), Facultad de Derecho, Valencia, 1976.
} 
embargo, ese triunfo no debe entenderse únicamente como resultado del nuevo marco de sinceridad electoral. Después de todo, eran ciudades que tenían más posibilidades de reflejar el verdadero estado de la opinión pública tras la implantación del sufragio universal masculino ${ }^{5}$. Más bien resulta necesario aludir a la fuerza alcanzada por el movimiento republicano desde el agrupamiento de sus familias en torno a Unión Republicana (UR) y la extraordinaria actividad que el partido mostró desde su creación.

\section{La formación de la Unión Republicana y la organización de las Elecciones a Cortes de 1903}

A comienzos del siglo $\mathrm{xx}$ los republicanos se encontraban en un nuevo escenario dentro de su compleja evolución desde comienzos de la Restauración ${ }^{6}$. Sus facciones habían oscilado entre la cohesión suscitada por un rechazo unánime del Estado centralizado y la fragmentación en torno a aspectos como el modelo de organización territorial, el anticlericalismo y el procedimiento a seguir para forzar la caída del régimen ${ }^{7}$. A ello se unía la dispar composición social de sus integrantes, que daba lugar a una cultura agrietada por la coexistencia de profesionales liberales que privilegiaban las tertulias democráticas y obreros que apostaban por la actividad callejera ${ }^{8}$. Varios conatos de unión habían fracasado por la discrepancia de sus líderes con respecto al contenido de sus programas ${ }^{9}$. Esas divergencias fueron una losa insalvable para el movimiento y le incapacitaron para sacar partido de la mayor competitividad electoral exis-

5 Carlos Dardé, La aceptación del adversario. Política y políticos de la Restauración, 1875-1900, Biblioteca Nueva, Madrid, 2003, pp. 232-257.

6 Carlos Dardé, «La larga noche de la Restauración, 1875-1900», en Nigel Townson (ed.), El republicanismo en España (1830-1977), Alianza, Madrid, 1994, pp. 113-138.

7 Javier de Diego, «La cultura política de los republicanos finiseculares», en Historia Contemporánea, n. ${ }^{\circ}$ 37, 2008, pp. 409-440.

8 Ángel Duarte: «Cultura republicana», en: Carlos Forcadell y Manuel Suárez Cortina (coord.), La Restauración y la República 1874-1936. Vol. III, Marcial Pons-PUZ, Madrid, 2015, pp. 229-254.

9 Las tendencias en las que se dividía el republicanismo eran el federalismo en el ala izquierda, el progresismo de José María Esquerdo (defensor de la vía revolucionaria de acceso al poder) y Fusión Republicana, organización que confluye con los progresistas en otra suprapartidista denominada Unión Nacional Republicana. En: Manuel Suárez Cortina, El Partido Reformista, 1912-1931, Tesis Doctoral, Universidad de Cantabria, 1985. 
tente desde la implantación del sufragio universal masculino en 1890. De hecho, las citas electorales que siguieron a esa normativa demostraron que los republicanos tenían recursos suficientes para movilizar a los madrileños siempre que estuvieran disciplinados ${ }^{10}$. Sin embargo, ese esperanzador porvenir se desplomó pronto. Los monárquicos taparon las fallas del sistema electoral, pero más decisivo fue que rebrotara el fraccionamiento orgánico de los republicanos en torno a familias distanciadas en términos de filosofía política, estrategias y bases sociales ${ }^{11}$.

Tras la crisis del 98 los republicanos retomaron la senda unitaria. La Monarquía parecía incapaz de levantar a un país deprimido tras la pérdida de las colonias, los liberales habían agotado su último turno sumidos en la disidencia tras la salida de José Canalejas, el trasvase de los gamacistas al Partido Conservador y la muerte de Sagasta y los conservadores mostraban divergencias polarizadas en torno a Silvela y Fernández Villaverde. En ese marco, los republicanos se consideraban como el sector más legitimado para abanderar el movimiento regeneracionista que siguió al desastre y sobre ese basamento afrontaron la necesidad de recomponer sus estructuras organizativas. El camino hacia la unidad fue complejo pero no se vio interrumpido. El republicanismo catalán fue el primero en pronunciarse a favor de la unificación a comienzos de 1901, seguido por el de Málaga (donde ese mismo año se formó una Junta de Unión Republicana elegida por sufragio universal) y el de Almería, pionero en la consecución de una reunificación que apoyaron los federales e incluyó las reivindicaciones del proletariado local ${ }^{12}$. El ideal unitario defendido en esta localidad, demandado por los integrantes de la agrupación «Germinal» (adscrita al republicanismo centrista), tomó forma definitiva con el mitin propagan-

10 Destacan los triunfos en las elecciones municipales de 1891 y en las generales de 1893. En: Santiago de Miguel, Madrid, los retos de la modernidad. Transformación urbana y cambio social (1860-1931), Tesis Doctoral, UCM, Madrid, 2015.

11 Manuel Suárez Cortina, El gorro frigio. Liberalismo, Democracia y Republicanismo en la Restauración, Biblioteca Nueva, Madrid, 2000 y Demetrio Castro (coord.), Líderes para el pueblo republicano: liderazgo político en el republicanismo español del siglo XIX, Universidad Pública de Navarra, Pamplona, 2015.

12 Fernando Arcas Cubero: «Aportación a la historia del republicanismo malagueño: la «Unión Republicana» y las elecciones de 1903», en: Boetica. Estudios de Arte, Geografía e Historia , n. ${ }^{\circ}$ 5, 1982, pp. 225-257 y M. ${ }^{\text {a }}$ Dolores Jiménez: «El republicanismo almeriense a comienzos del siglo Xx. Organización y trayectoria de la Unión Republicana», en: Catalina Martínez Padilla (ed.), A la memoria de Agustín Díaz Toledo, Servicio de Publicaciones de la Universidad de Almería, Almería, 1995, pp. 317-327. 
dista pronunciado por Nicolás Salmerón en el teatro Variedades en septiembre de $1902^{13}$.

El llamamiento de Salmerón a la concordia republicana en Almería tuvo ecos significativos en forma de adhesiones a la causa, siendo algunas de las más conocidas la de José Nakens en El Motín (diario que dirigía y desde el cual había apostado por una acción coordinada), la del fundador de El País Antonio Catena y la de Fernando Lozano, impulsor de Las Dominicales del Libre Pensamiento ${ }^{14}$. La consolidación de ese espíritu llegó después con episodios claves como el mitin de Salmerón en Castellón de enero de 1903, donde señaló la necesidad de lograr un definitivo acercamiento de posturas entre las facciones del movimiento, o las reuniones de representantes de Fusión Republicana en febrero, que acordaron convocar una asamblea general para constituir un único partido con un solo jefe. Gran trascendencia tuvo también el apoyo que Joaquín Costa brindó a la unidad republicana, clave para cautivar a las masas neutras, término que aludía una clase media formada por comerciantes, propietarios y patrones ajenos a la política ${ }^{15}$. Todos estos esfuerzos culminaron con la Asamblea Magna del 25 de marzo de 1903 en el Teatro Lírico de Madrid. Allí nació con el apoyo del grueso del republicanismo (a excepción de los progresistas de José María Esquerdo y de un sector del Partido Federal) y con la adhesión de sectores societarios obreros una nueva Unión Republicana

13 Fernando Martínez López, Masones, republicanos y librepensadores en la Almería contemporánea (1868-1945), Universidad de Almería, Almería, 2010, pp. 151-154.

14 Manuel Pérez Ledesma: «José Nakens (1841-1926): pasión anticlerical y activismo republicano », en: Isabel Burdiel y Manuel Pérez Ledesma (eds.), Liberales, agitadores y conspiradores. Biografías heterodoxas del siglo XIX, Espasa, Madrid, 2000, pp. 301-330; Santiago Jaén: «Antonio Catena Muñoz: propietario y fundador de El País, el gran diario republicano de la Restauración», en: Elucidario, n. ${ }^{\circ}$ 7, 2009, pp. 155-168 y Javier de Diego: «Activistas anticlericales y militantes republicanos: José Nakens, Fernando Lozano y la Unión Republicana de 1903», en: Comunicaciones. Congreso Nicolás Salmerón y Alonso. A propósito del centenario de la Unión Republicana de 1903, Almería, Universidad de Almería, 2003, pp. 344-361.

15 La adhesión de Costa a UR se enmarca en su etapa de «realismo político» y se explica por la propia ingenuidad que representó su intento de crear un partido político nuevo y por la coherencia de UR con sus ideales, reflejada en un programa que prometía instrucción primaria gratuita, juicio por jurados, protección social más eficiente y postura crítica hacia la oligarquización de los partidos. Véanse: Carlos Forcadell, «Proyecto nacional de Joaquín Costa», en El pensamiento de Joaquín Costa, Centro de Estudios de Monzón, Monzón, 1997, pp. 49-56 y Ángel Duarte: «Joaquín Costa, republicano», en Cristóbal Gómez (coord.), Joaquín Costa y la modernización de España, Congreso de los Diputados, Madrid, 2011, pp. 251-280. 
(UR) liderada por Salmerón. Su designación le permitió culminar una larga trayectoria política, evitándose además el vacío de referentes históricos en el movimiento tras las muertes de Pi i Margall y Castelar ${ }^{16}$.

No es nuestro propósito detenernos en las características de UR, apuntadas en otros trabajos ${ }^{17}$. Basta señalar que su objetivo era ir más allá de una coalición electoral y reanimar a un país excitado por «el fracaso de la Monarquía en todos los órdenes de la existencia nacional» ${ }^{18}$. Esto explica que Duarte haya destacado la voluntad de permanencia del partido, espoleado por la recuperación del contenido social de la esperanza republicana ${ }^{19}$. En aquel momento confluían también en las diversas ramas del republicanismo unos valores (crítica a la institución monárquica y vindicación de los derechos ciudadanos) que impulsaron la estrategia unitaria ${ }^{20}$. Sin embargo, resulta innegable que las discrepancias entre los partidarios de la revolución y de la lucha legal no habían desaparecido, como tampoco las incompatibilidades en nociones de política, cuestión religiosa y regionalismo. Aquí se encuentran las causas que llevaron a la posterior crisis de UR, reflejadas en la aparición de las facciones reformista y radical.

No obstante, es fundamental remarcar dos hechos fundamentales. En primer lugar, la UR fue un proyecto que convirtió al parlamentarismo en el principal objetivo de la acción política del movimiento frente a un método insurreccional que pasó a un segundo plano. Suárez Cortina vislumbró una acentuación del proceso de flexibilización doctrinal coincidente con la aparición del partido, defensor del seguimiento de procedimientos electorales para la búsqueda de la democracia republicana ${ }^{21}$. En segundo lugar, la UR representó un esbozo de partido de masas que buscó una co-

16 Ángel Duarte, «La Unión Republicana de 1903 ¿eslabón o gozne?», en Fernando Martínez (ed.), Nicolás Salmerón y el republicanismo parlamentario, Biblioteca Nueva, Madrid, 2007, pp. 147-163.

17 Manuel Suárez Cortina, «La Unión Republicana: el republicanismo español a comienzos del siglo XX», en Historia 16, n. ${ }^{\circ}$ 143, 1988, pp. 23-34.

18 Nicolás Salmerón, Instrucciones para la organización del partido Unión Republicana, Imprenta de la Prensa de Madrid, Madrid, 1903.

19 Ángel Duarte: «La Unión Republicana de 1903»..., op. cit., pp. 162-163.

20 Javier de Diego, Imaginar la República. La cultura política del republicanismo español, 1876-1908, CEPC, Madrid, 2008, pp. 347-376.

${ }^{21}$ Manuel Suárez Cortina: «La quiebra del republicanismo histórico, 1898-1931», en: Nigel Townson (ed.), El republicanismo en España (1830-1977), Alianza Editorial, Madrid, 1994, pp. 145-146. 
municación directa con el electorado y una estructura organizativa moderna. Diversos estudios han revelado la fase de expansión que el republicanismo vivió en diferentes regiones al hilo de esta estrategia, traducida en notables campañas propagandísticas y en la creación de comités. Este fenómeno ha sido analizado en algunas provincias del norte y en diversas regiones del sur, siguiéndose la evolución del tejido asociativo republicano $^{22}$. La promoción de casinos y círculos también ha sido objeto de atención en aras de resaltar su preocupación por la proletarización de los espacios de sociabilidad y por articular centros de difusión del ideal republicano $^{23}$. Todo ello representaba la importante contribución de UR a las transformaciones que se estaban operando en la política desde comienzos del siglo Xx y que abrieron la senda de su modernización, formalizada después con la Conjunción Republicano-Socialista ${ }^{24}$.

Sin embargo, no hay que perder de vista que el proceso de articulación del andamiaje político de Unión Republicana también se explicaba por la proximidad de las elecciones legislativas. No tardó Salmerón en lanzar una circular que planteaba la celebración de mítines simultáneos en las capitales de provincia el 12 de abril como primer paso para una movilización que recogiera un amplio estado de los elementos con que contaba el partido en cada circunscripción ${ }^{25}$. El político almeriense comprendió la necesidad de invertir esfuerzos en la difusión de las candidaturas aprovechando el descrédito de los partidos dinásticos. Si la ascendencia de Lerroux y de Blasco Ibáñez sobre los núcleos obreros y mercantiles de Bar-

22 Pedro López, Élites y poder: cambio estructural y dinámica política bajo el caciquismo liberal: La Rioja, 1890-1930, Instituto de Estudios Riojanos, Logroño, 2001; José Luis Casas y Francisco Durán (coord.), El republicanismo en la historia de Andalucía, Patronato Niceto Alcalá-Zamora y Torres, 2001; Román Miguel González, La montaña Republicana. Culturas políticas y movimientos republicanos en Cantabria (1874-1915), Ayuntamiento de Santander, Santander, 2007; Jon Penche, Republicanos en Bilbao (1868-1937), Universidad del País Vasco, Leioa, 2010; Antonio López Villa, El republicanismo en Sevilla a comienzos del siglo XX, Ayuntamiento de Sevilla, Sevilla, 2010; Unai Belaustegi: «El republicanismo en Gipuzkoa, 1868-1923: organización y desarrollo político», en: Sancho el Sabio, n. ${ }^{\circ}$ 37, pp. 133-157, 2014 y Santiago Jaén, Entre tierra y plomo. Historia del republicanismo jiennense (1849-1923), Ediciones Carena, Barcelona, 2014.

${ }^{23} \mathrm{M}^{\mathrm{a}}$. Dolores Jiménez, Clientelismo político y comportamiento electoral en Almería durante la Restauración (1902-1923), Tesis Doctoral, Universidad de Almería, 2002, pp. 86-87.

${ }^{24}$ Antonio Robles: «La Conjunción Republicano-Socialista: una síntesis de liberalismo y socialismo», en: Ayer, n. . 54, 2004, pp. 97-127.

25 La Publicidad, 1 de abril de 1903. 
celona y Valencia garantizaba el triunfo de UR en ambas ciudades ${ }^{26}$, en Madrid la confianza no era absoluta. Después de todo era la sede de la Corte, el lugar donde los organismos locales podían echar mano de variados recursos del arte electorero. La UR debía desarrollar una campaña enérgica para vencer y así lo hizo. Primero, reunió a los comités republicanos de los diez distritos en el Círculo Republicano de la calle de Pontejos para tratar sobre preparativos electorales ${ }^{27}$. Conformó así el esqueleto de su estructura organizativa, abriendo después centros electorales en cada distrito para establecer un contacto directo con sus correligionarios ${ }^{28}$. Allí se les decía cuáles eran los colegios donde debían votar y se comprobaba si aparecían omitidos del censo para después elevar reclamaciones a la Junta Central del Censo Electoral, organismo que resolvía estas cuestiones según el artículo 10 de la ley electoral de 1890 .

Algunos de estos centros electorales se mostraron especialmente activos hasta la votación, asumiéndose en ellos prácticas políticas avanzadas. En el distrito de Inclusa se abrieron listas de suscripción para costear trabajos electorales, administrándose las recaudaciones desde la sede central de la calle de la Encomienda. A ella acudieron grupos de obreros que se ofrecieron a ser instruidos como interventores y a realizar trabajos de propaganda gratuitos en los comicios, siendo este escenario muy similar al presentado en el Círculo Republicano de Audiencia situado en la calle de Pontejos. En ese mismo punto se reunieron los correligionarios de Hospicio, que nombraron una comisión de cuarenta republicanos para realizar los trabajos electorales de las secciones del casco antiguo y otra subcomisión de treinta para dirigir la lucha en la barriada de Cuatro Caminos. El presidente de aquel centro entregó a los republicanos más antiguos de los

${ }^{26}$ Ramir Reig, Obrers $i$ ciutadans. Blasquisme i moviment obrer, Institució Alfons el Magnànim, Valencia, 1982 y Joan B. Culla, El republicanisme lerrouxista..., op. cit.

27 Una panorámica general sobre la actividad de los centros republicanos en: Pere Gabriel, «La construcción de una cultura política popular: centros y actividades republicanas bajo la Restauración», en Claudia Cabrero et. al. (coords.), La Escarapela Tricolor. El republicanismo en la España contemporánea, KRK Ediciones, Universidad de Oviedo, 2008, pp. 87-114.

${ }^{28}$ Los centros electorales de UR en los distritos de Madrid fueron: Latina (Café de San Millán), Palacio (Sociedad de Fotograbado de Morán y Cía en Limón 13), Inclusa (Encomienda 7); Hospital (Liceo Rius en Atocha 68), Buenavista (farmacia de Génova 7 y fábrica de calzado de Francisco Rodríguez, hermano del candidato Constantino, en General Pardiñas 40), Universidad (Palma 32), Hospicio (Café de Santa Engracia en Santa Engracia 41), Centro (Petit Fornos en Capellanes 1), Audiencia (Tertulia Progresista en Pontejos 4) y Congreso (Liceo Rius). 
barrios censos para contribuir a su depuración, dilucidando quiénes eran sospechosos de concurrir a las urnas como falsos electores. En cuanto a los republicanos de Congreso, su centro electoral sirvió como punto de reunión para correligionarios de variada posición social. Abogados, médicos, farmacéuticos y representantes de sociedades obreras confluyeron allí para nombrar una comisión de siete representantes que visitara a los vecinos afines al movimiento escuchando sus reclamaciones ${ }^{29}$.

Huelga decir que para los republicanos resultaba crucial depurar un censo que sobredimensionaba el elemento oficial de la Corte, de ahí que Salmerón determinara que entre las principales acciones del partido debía figurar la solicitud de las inclusiones de ciudadanos que gozaran del derecho de sufragio y la exclusión de los que aparecieran en la estadística de forma indebida. La circular que extendió el 7 de abril de 1903 aludía a estas cuestiones y expresaba la necesidad de estudiar las listas observando que aquellas comprendiesen la edad, el domicilio, la profesión y el tiempo de residencia de los electores, así como una relación de fallecidos y de los que hubieran perdido el derecho de voto por incapacidad o pérdida de vecindad $^{30}$.

Miguel Morayta y Manuel de Llano y Persi, candidatos de la UR por Madrid, siguieron las recomendaciones de su líder y recopilaron las reclamaciones recogidas en los centros electorales en una exposición elevada a la Junta Central del Censo Electoral. Uno de su propósitos fue el de restringir las ayudas, contrarias a la ley electoral, con que pudiesen contar los monárquicos. La más clara guardaba relación con el estamento militar. En elecciones previas había sido una constante el ejercicio del sufragio por soldados acuartelados adoctrinados por sus jefes para brindar un apoyo unívoco a las candidaturas adictas. Amparados en el párrafo $3 .^{\circ}$ del primer artículo de la ley electoral de 1890, los republicanos recalcaron la incapacidad electoral de aquellos individuos que formasen parte de los ejércitos de mar y tierra o de otros cuerpos e institutos armados dependientes del Estado, la provincia o el municipio que estuvieran en filas. Si las deficiencias del censo con respecto al punto anterior podían observarse en secciones como la que comprendía el Cuartel de Alabarderos (distrito de Palacio) o la 14. ${ }^{\text {a }}$ de Hospicio (donde de 490 electores, 460 eran guardias civiles del Palacio de Bellas Artes), también quedaban al descubierto otras

${ }_{29}$ El País, $1-9$ de abril de 1903.
30 El Motín, 19 de abril de 1903.

Historia Contemporánea 53: 553-591 
infracciones que los republicanos denunciaron con insistencia. Así, la posible inflación del censo mediante la incorporación de individuos desconocidos o empadronados en viviendas inexistentes justificó la petición de listas de fallecidos. La solicitud encontró la disposición favorable de la Junta Provincial del Censo Electoral, que emitió una circular para subsanar los errores advertidos ${ }^{31}$. Además, en los días previos a la votación, este organismo remitió relaciones de electores que tuvieran en suspenso el ejercicio del voto ${ }^{32}$.

Para los republicanos, la autentificación del voto también exigía contar con notarios que solventaran las dudas que planteara la interpretación de la ley electoral. Su cometido era impartir conferencias a los interventores republicanos explicándoles los derechos que la normativa les concedía hasta la votación ${ }^{33}$. También debe valorarse dentro de esta línea la búsqueda de un adoctrinamiento del electorado mediante la difusión de folletos que contenían observaciones sobre la aplicación del sufragio universal. Los republicanos adoptaron esa iniciativa e incitaron a sus correligionarios a estudiar los puntos tratados en ese documento para frenar los chanchullos que pudieran cometerse en las mesas, especialmente en lo referente al robo de actas por parte de sus presidentes. Algunos candidatos extremaron estas medidas de una forma que pocas veces se había visto. Constantino Rodríguez y Jacinto Octavio Picón, miembros de la UR en Madrid, giraron visitas al alcalde, marqués de Portago, para requerirle la lista de los presidentes de mesas ${ }^{34}$. Ambos sabían del derecho que les acogía para hacer una petición que, sin embargo, fue rechazada, negándose también el alcalde a admitir el requerimiento notarial. El partido apoyó sin ambages su iniciativa y condenó la respuesta del alcalde encomendando a su comisión de letrados la imposición de una querella contra aquel.

Los mítines, planteados como termómetros para medir el impulso del nuevo partido, fueron un éxito. En Madrid, los primeros tuvieron lugar a comienzos de abril, escogiéndose las zonas de Ventas del Espíritu Santo y Plaza de Toros para atraer a una población a la que se hablaba de la inexistencia de leyes favorables a su progreso y del incumplimiento de las ya aprobadas, relativas a los accidentes de trabajo y a la prohibición de

31 Gaceta de Madrid, n. ${ }^{\circ}$ 105, 15 de abril de 1903.

${ }^{32}$ Los preparativos de las elecciones en: Archivo de Villa de Madrid, Secretaría, (AVS), 14-273-43.

${ }^{33}$ El País, 19 de abril de 1903.

34 Ibid. 
la actividad laboral para los menores de catorce años. No obstante, el primer gran mitin se celebró en el Frontón Central de la calle de Tetuán el 12 de abril. La reunión, precedida de un escrito de los federales en el que apoyaban la candidatura oficial de UR para evitar divisiones en el voto, congregó a 8.000 personas. El cénit del entusiasmo llegó con los rugidos del León de Graus, que determinó, como objetivos de la campaña, lograr una revolución desde arriba (por parte de elementos republicanos) e inspirar mayor confianza a las masas neutras. A ese mitin siguieron otras reuniones organizadas por los correligionarios del partido de diferentes distritos (Universidad y Hospicio el 14 y 18 de abril) y de áreas colindantes fuera del término municipal (Puente de Vallecas).

De manera paralela comenzaron los discursos de los candidatos en los centros electorales. En algunos se instruía a los agentes electorales del partido aconsejándoles la realización de sondeos de votos por barrios mediante visitas a los vecinos que formaran parte de la masa neutra. Aquella medida buscaba hacer una lista previa de la tendencia del voto republicano, útil para formular protestas más enérgicas. Estos esfuerzos estuvieron ausentes en la campaña realizada por los monárquicos, que únicamente protagonizaron reuniones puntuales para presentar a sus candidatos $^{35}$. Defendieron el orden vigente y entendieron los comicios como un plebiscito entre dos formas de gobierno. La Época destacó la imparcialidad gubernamental, visible en el abandono de los procedimientos utilizados para fabricar mayorías ${ }^{36}$. El Imparcial confiaba en la victoria monárquica basándose en una supuesta unidad de sus candidatos, en el auxilio de los funcionarios y en el carácter favorable que para ellos presentaba el censo $^{37}$. No obstante, la mayoría de diarios tuvo que admitir las altas probabilidades de éxito de los republicanos ${ }^{38}$.

Los trabajos de UR culminaron con una ofensiva final en la que se publicaron circulares de Salmerón advirtiendo de la repercusión que podía tener la victoria en Madrid, cartas de Constantino Rodríguez a la clase mercantil para que abandonara el retraimiento y una relación detallada de los mítines previos a la votación. La representación de éstos últimos sobre el espacio urbano deja entrever la importancia que se concedió a la con-

35 Véase la reunión celebrada en el Nuevo Círculo Liberal en: El Globo, 13 y 14 de abril de 1903.

36 La Época, 25 de abril de 1903.

37 El Imparcial, 25 de abril de 1903.

38 El Diario Universal y Heraldo de Madrid, 13 de abril de 1903. 
quista de zonas que no habían generado perfiles políticos concretos, situadas más allá del Ensanche, sin un clientelismo desarrollado y ajenas al turnismo por los sectores sociales que habitaban en ellas. Eran espacios como Bellas Vistas, Cuatro Caminos, Prosperidad o Guindalera, lugares donde asistieron los candidatos con programas dotados de un contenido social, significando los derechos que amparaban a la población obrera. La situación era distinta en los distritos del sur del casco antiguo, de abolengo republicano desde el Sexenio Democrático. Allí intervenían figuras históricas del republicanismo como Manuel de Llano y Persi, recordando los tiempos en que había ejercido como Teniente de Alcalde del distrito de Latina. Algo parecido se podía decir de Inclusa, al ser Lucio Catalina quien tomó la voz cantante en los mítines celebrados en las Escuelas Pías de San Fernando. Catalina había sido un puntal en el Círculo Republicano del distrito desde que el republicanismo salió de la clandestinidad y debía a sus electores la concejalía lograda en 1901.

El empeño que UR puso en perfeccionar los conocimientos de los interventores y en demostrar intentos de coacción fue la última muestra de una campaña bien articulada. En el caso de los primeros, una de las medidas adoptadas para su adoctrinamiento fue señalar las normas que debían regir determinados actos electorales. En lo referente a la constitución de las mesas, se les instaba a acudir a los colegios hora y media antes del inicio de la votación para fiscalizar a los interventores monárquicos, observando si estaban capacitados para esa función. En lo que respecta a la votación, debían confrontar los nombres de los que concurriesen a las urnas con las listas de la sección, que llevarían al efecto notas marginales con nombres de fallecidos, incapacitados y ausentes ${ }^{39}$. El análisis del escrutinio era la parte más importante de este proceso. Los interventores debían confrontar el número de papeletas de la urna con el de votantes en las listas, cuidar de que se extendieran dos certificaciones iguales a la del escrutinio fijada en la parte exterior del colegio electoral (una para la Secretaría de la Junta Central del Censo y otra para la Junta Provincial) y exigir que se diera a los electores certificados del escrutinio.

Las tareas para la detección de casos de coacción también se intensificaron. Desde la candidatura republicana había sospechas de que se habían enviado circulares a los empleados del Ferrocarril del Norte y a los de la

39 Estas notas son identificables en las listas de las secciones, en: AVS, 14-273-43, 14274-1 y $14-275-1$. 
Compañía Madrileña de Electricidad pidiéndoles que emitieran su voto en favor de la candidatura monárquica. También circulaban rumores de que se habían dado instrucciones a empleados de consumos en una línea similar a la anterior (bajo pena de cesantía para quienes la infringieran) y a los abastecedores del Palacio Real. Finalmente, no faltaban denuncias contra la actitud mostrada por algunos inspectores de policía, empecinados en recorrer puestos callejeros para recomendar la candidatura ministerial ${ }^{40}$. Estas eran tareas claves para aminorar posibles derrotas en los distritos acomodados menos proclives a la causa del partido.

Finalmente, las actuaciones de UR buscaron fomentar la disciplina entre sus correligionarios. Esa positiva conducta atañía a los electores, a quienes se les instó a votar a primera hora de la mañana y a acompañar a los interventores mientras se realizaba el escrutinio. De esta forma podrían frenar las rondas de falsos electores, detectar candidaturas impresas en las que se hubiera sustituido el nombre de algún republicano y evitar que los presidentes de mesas secuestrasen las actas originales para llevar otras en blanco a la Junta Provincial del Censo Electoral. Sin embargo, la disciplina republicana también sobrepasaba los límites municipales. Al mitin del Frontón Central ya asistieron representaciones de distintos puntos de la provincia, nombrando comisiones que organizasen los comités republicanos de sus lugares de origen. No obstante, los apoyos llegaron a tal punto que incluso muchos de los inscritos en Alcalá de Henares, Villaverde, Navalcarnero, Ciempozuelos y El Escorial se citaron en Madrid el día de la votación para frenar las rondas electorales ${ }^{41}$.

UR siguió idénticas estrategias en otros núcleos urbanos. En Barcelona, la actividad propagandística desarrollada por la candidatura del partido resulta visible en la movilización de sus correligionarios por medio del espacio propio (los comités y los clubes) y del espacio público (las calles a través de los mítines). Las instrucciones que UR difundió a electores (para inspeccionar los colegios), repartidores de candidaturas (para evitar coacciones) e interventores (para supervisar el escrutinio) revistieron la misma rigurosidad que en Madrid. Afloraban las mismas prácticas democráticas con las revisiones de los censos y las reuniones de los electores en las secciones, orquestadas a nivel particular por los comités y los círculos instructivos y a nivel general por el centro lerrouxista de Fraterni-

\footnotetext{
40 El País, 23 y 24 de abril de 1903.

41 El País, 20 de abril de 1903.
} 
dad Republicana ${ }^{42}$. Las estrategias de encuadramiento de la militancia republicana, ya notables en los años anteriores gracias la acción de Lerroux, adquirieron nuevos matices, gracias al funcionamiento de oficinas electorales con personal retribuido en las semanas previas a los comicios, a la inauguración de nuevos locales para albergar a los elementos de base del partido y a la celebración de actos populares apartados de la lógica de los solemnes banquetes que incluían romerías democráticas en las afueras de la ciudad ${ }^{43}$.

Lo mismo se podría decir de Sevilla, donde los interventores operaron de la misma forma que sus homólogos madrileños anotando en los márgenes de los censos los fallecidos, incapacitados y ausentes que debían ser excluidos del derecho de voto ${ }^{44}$, o de Valencia, donde el antiguo centro de Fusión Republicana sirvió para atender las consultas de los correligionarios, resueltas personalmente por los candidatos de la UR Emilio Menéndez Pallarés y Vicente Blasco Ibáñez, actuando los comités de los distritos urbanos como espacios orientados a la formación de comisiones de vecinos que participaran en los trabajos electorales del partido ${ }^{45}$. Pese a todo, es necesario señalar que el de la capital levantina supone un caso paradigmático en el contexto de estas elecciones. En ella se presentaba una forma avanzada de hacer política dividida en torno al blasquismo de Blasco Ibáñez y el sorianismo de Rodrigo Soriano, recientemente separado del partido $^{46}$. Las elecciones en Valencia estuvieron marcadas por los cruces de declaraciones entre los partidarios de uno y de otro, de ahí que el propio Salmerón manifestara a Blasco Ibáñez su deseo «de terminar con el triste espectáculo que ofrece la republicana Valencia, justamente en el instante en que España entera despierta a la vida del republicanismo, contrastando los escándalos de aquí con la fe y el entusiasmo del resto de la Península» ${ }^{47}$.

42 La Publicidad, 18-26 de abril de 1903.

43 Joan B. Culla, El republicanisme lerrouxista..., op. cit., pp. 64-67 y Ángel Duarte, Història del republicanisme a Catalunya, Eumo Editorial, Barcelona, 2004, pp. 157-162.

44 Antonio López Villa, El republicanismo en Sevilla ..., op. cit., pp. 71-85.

45 El Pueblo, 14-26 de abril de 1903.

46 El blasquismo ha sido tratado desde diferentes variables. Dos estudios destacados, situados en cronologías extremas, son: Alfons Cucó, Sobre la ideología blasquista, Tres i Quatre, Valencia, 1979 y Luz Sanfeliu, Republicanas. Identidades de género en el blasquismo (1895-1910), Publicacions Universitat de Valencia, Valencia, 2005.

47 El Pueblo, 17 de abril de 1903. 


\section{La movilización estudiantil y su influencia en la campaña electoral republicana}

En las elecciones generales de 1903, el republicanismo sacó provecho de la agitación estudiantil que se registraba en distintas ciudades (Madrid, Barcelona, Valencia y Zaragoza) y que hundía sus raíces en la postura mostrada por algunas de sus principales figuras intelectuales, que requirieron al gobierno una actitud reformadora en el apartado educativo desde comienzos del Novecientos. Esa voluntad nacía de la percepción negativa de la universidad, enquistada en un modelo elitista de rutinas académicas, y se tradujo en la creación de asociaciones de filiación republicana, como las Uniones Escolares ${ }^{48}$. El ambiente estudiantil se alteró progresivamente, con las protestas de los alumnos de las facultades de Medicina contra la obligación de cursar distintas especialidades incorporadas al plan de estudios mediante Real Decreto de 21 de septiembre de 1902 y contra la separación entre asignaturas teóricas y sus clínicas ${ }^{49}$. La desatención de las demandas estudiantiles llevó a la convocatoria de huelgas y la respuesta ministerial se tradujo en cierres de facultades, expulsión de alumnos y violentos enfrentamientos.

En Madrid, los alumnos de Medicina y Farmacia organizaron mítines de relevancia como el del Frontón Central del 29 de marzo. Los estudiantes, con el apoyo del rector de la Universidad Central, del decano de la Facultad de Medicina y de varios catedráticos, solicitaron al gobierno dar mayor amplitud a la enseñanza para elevar el nivel intelectual de España. Reclamaron una nueva ley de enseñanza, la ampliación de horarios en las bibliotecas, el aumento del presupuesto de Instrucción Pública, la aprobación de una Ley de Policía Sanitaria y la construcción de un Hospital Clínico y de un edificio exclusivo para Facultad

48 Las Uniones Escolares actuaban como sociedades destinadas a lograr la asociación de todos los estudiantes que cursaran alguna de las enseñanzas que se daban en los centros oficiales. En el caso de la de Madrid, su objetivo era crear un círculo escolar donde se establecieran cátedras, bibliotecas, actividades de recreo, conferencias y veladas fomentando el compañerismo. Véase: Unión Escolar. Asociación General de Estudiantes Españoles declarada benéfica por R. O. de 30 de agosto de 1900, Establecimiento Tipográfico de A. Pérez, Madrid, 1900 y Eduardo González Calleja, Rebelión en las aulas: movilización y protesta estudiantil en la España Contemporánea (1865-2008), Alianza, Madrid, 2009, pp. 72-90.

49 Germán Perales, Católicos y liberales: el movimiento estudiantil en la Universidad de Valencia (1875-1939), Universidad de Valencia, Valencia, 2011, pág. 178. 
de Farmacia. También se pidió conceder prioridad a los alumnos de Medicina y de Farmacia para ocupar las plazas destinadas a servicios farmacéuticos en hospitales y las de practicantes en Casas de Socorro ${ }^{50}$. Las demandas se extendieron a otros estudiantes como los de la Escuela Superior de Artes e Industrias y los de la Escuela de Agricultura. Estos últimos levantaron protestas ante el Real Decreto de 6 de marzo de 1903, que admitía a las oposiciones para ayudantes de montes a cualquier persona aun cuando no tuviera el título de perito mercantil, y presentaron quejas al Ministerio de Instrucción Pública por las deficiencias del centro donde cursaban estudios.

Lo ocurrido en Salamanca los días 1 y 2 de abril provocó que esta tensa situación estallara en mil pedazos. Sus estudiantes apoyaron las huelgas de marzo coordinados por la Unión Escolar y protagonizaron manifestaciones, pero nada fuera de la lógica de otros núcleos urbanos $^{51}$. Los trágicos sucesos posteriores derivaron de una reyerta entre un estudiante y un empleado ferroviario que culminó con la detención del primero tras ser llevados a declarar al Gobierno Civil. Los compañeros del detenido nombraron una comisión que visitara al gobernador para pedir su libertad, pero ante la negativa de la autoridad organizaron una protesta que terminó en cargas de la Guardia Civil, saldadas con cuatro muertos. Al conocerse estos hechos se produjeron graves disturbios en Madrid. Primero en la Universidad Central y después en la Puerta del Sol, desde donde los manifestantes se dirigieron a la Presidencia del Consejo de Ministros y al Gobierno Civil. La situación más crítica llegó el 4 de abril ${ }^{52}$. Reunidos frente a una universidad custodiada por guardias de Seguridad, los estudiantes emprendieron una marcha espontánea hacia la Plaza de la Cebada. Los vivas a Salmerón y los mueras al gobierno fueron secundados por vendedoras ambulantes y vecinos al llegar a la calle de Toledo. Los guardias de orden público ordenaron el cierre del mercado de la Cebada provocando la ira de quienes tenían sus puestos en los alrededores. Los manifestantes abandonaron la zona y pusieron rumbo a la Puerta del Sol, donde prosiguieron los vítores a la República, acompañados por interpretaciones de La Marsellesa. La rapidez

50 El País, 30 de marzo de 1903.

51 Jean-Claude Rabaté, 1900 en Salamanca: guerra y paz en la Salamanca del joven Unamuno, Ediciones Universidad de Salamanca, Salamanca, 1997.

${ }^{52} \mathrm{La}$ reconstrucción de los hechos a través de: El País, Heraldo de Madrid, El Globo, El Liberal, El Día y El Imparcial (4-8 de abril de 1903). 
con que se desarrollaba la jornada alcanzó sus mayores cotas cuando los allí congregados decidieron avanzar hacia la Fábrica de Tabacos para obtener el apoyo de las cigarreras. Universitarios y pequeños comerciantes entendían que contar con el respaldo de ese sector otorgaría más ímpetu a la manifestación, pero las fuerzas de orden público evitaron la unión de los grupos donde la situación podía tornarse más violenta: en los barrios bajos.

La manifestación adquirió proporciones importantes en la calle de Lavapiés. 3.000 personas enfilaron la vía a última hora de la tarde, alentados por los vecinos de la zona que se asomaban a los balcones. Los característicos sablazos de los motines de Corte, claves para mantener el orden en las zonas más acomodadas, perdían su efectividad en un espacio donde los manifestantes encontraron un apoyo abrumador. Algunos obreros bajaron de sus domicilios y arrancaron el empedrado de la calle para lanzar cascotes sobre los guardias. Las mujeres improvisaban proyectiles con las macetas de los balcones de sus casas. El aparente caos llevó a los guardias a iniciar los primeros disparos; preventivos primero, indiscriminados después. La batalla campal se saldó con diez detenidos, varios heridos de gravedad y un muerto: Martín Asunción, un joven de 19 años conocido como El Hospicia residente en la Plaza de Lavapiés. La represión culminó con un bando de José Sánchez Guerra en el que eximía a la clase estudiantil de haber instigado la batalla campal (dejando las responsabilidades a los vecinos de los barrios bajos) y en el que encomendaba a la Guardia Civil la prohibición de la formación de grupos que interrumpiesen el tránsito público y de cualquier manifestación no autorizada. Se suspendieron varios mítines de protesta y se establecieron cortapisas a la libertad de expresión. Incluso el entierro de El Hospicia se hizo en la clandestinidad, a sabiendas de que congregar a numerosos obreros y estudiantes republicanos.

Aquellas medidas levantaron fuertes censuras hacia Maura, que se limitó a subrayar la actitud violenta de los manifestantes ante una fuerza pública que únicamente podía salvarse de una avalancha abriendo fuego ${ }^{53}$. Las protestas llegaron desde diferentes grupos sociales. El Colegio de Abogados de Madrid publicó una nota en prensa, agrupaciones obreras enviaron telegramas de apoyo a la Unión Escolar y numerosos comerciantes cerraron sus establecimientos coincidiendo con los funerales de los

${ }^{53}$ El Imparcial, 5 de abril de 1903. 
estudiantes salmantinos. Sin embargo, fueron los universitarios quienes jugaron el papel más relevante. Los adscritos a la Juventud Escolar Republicana organizaron mítines para solicitar el sobreseimiento de las causas pendientes por delitos políticos, publicaron manifiestos de apoyo a UR por ver en el nuevo partido iniciativas de regeneración intelectual y pidieron la formación de nuevas asociaciones estudiantiles que actuasen como núcleos de propaganda política educativa ${ }^{54}$. Asumieron un cierto protagonismo en los mítines solicitando las dimisiones de los gobernadores civiles de ambas provincias y enviando comisiones a la ciudad castellana para portar coronas de flores a las víctimas. La Unión Escolar corroboró su participación en los disturbios de Lavapiés, pese a que Maura descartó su presencia en esa zona en un vano intento de atribuir los enfrentamientos a las clases populares ${ }^{55}$, e incluso organizó campañas de donativos para auxiliar a las verduleras que sufrieron daños en sus puestos durante las cargas producidas en la plaza de la Cebada.

La participación de los estudiantes no concluyó en aquellas jornadas. Ejercieron una intensa propaganda llenando de carteles las calles de cada distrito, participando en los mítines y formando puestos de guardia el día de la votación ${ }^{56}$. En los días previos a la votación convocaron reuniones en los salones de la Tertulia Progresista de la calle de Pontejos a las que asistieron numerosos estudiantes y obreros, así como distintas agrupaciones de jóvenes militantes en el partido como la Unión de Juventud Republicana, la Juventud Federal y la Asociación Escolar Republicana. Esta última, constituida el 18 de abril, planteaba en su programa fundacional organizar grupos mixtos de estudiantes y obreros que evitaran, durante la votación, coacciones y compras de votos por parte de los monárquicos ${ }^{57}$. La importancia que estos acontecimientos tuvieron antes de las elecciones es innegable y su visión global pone de relieve la protesta nacional contra Maura (especialmente intensa en Barcelona, Valencia y Zaragoza, donde se produjeron incidentes similares a los de Madrid) y la crítica situación de los partidos dinásticos.

54 El País, 28 de marzo de 1903.

55 La noticia que aludía a la ausencia de elementos estudiantiles en los altercados en: La Época, 4 de abril de 1903. La nota de Unión Escolar desmintiendo esa afirmación en: El País, 6 de abril de 1903.

56 Las Dominicales del libre pensamiento, 3 de abril de 1903.

57 El País, 19 de abril de 1903. 


\section{Cuestión de confianza. Radiografía de la jornada electoral en Madrid}

El escrutinio del 26 de abril de 1903 deparó para el republicanismo los resultados más positivos de su trayectoria electoral en la etapa de la Restauración. Obtuvo 36 escaños en las nuevas Cortes y sacó íntegras sus candidaturas en Madrid, Barcelona y Valencia, aunque también destacaron los resultados cosechados en capitales de provincia como Castellón, Cádiz, Salamanca, Granada, Palma de Mallorca, La Coruña, Tarragona, Logroño y Lérida. En correspondencia con su agitada campaña, la UR de Barcelona logró más de 35.000 votos, recabando el apoyo masivo de las capas obreras, pero también de unas clases medias fuertemente movilizadas. La relevancia de estos resultados en la capital catalana se evidencian en el hecho de que la mencionada cifra de votos fue la más elevada obtenida por una candidatura de izquierdas hasta abril de $1931^{58}$.

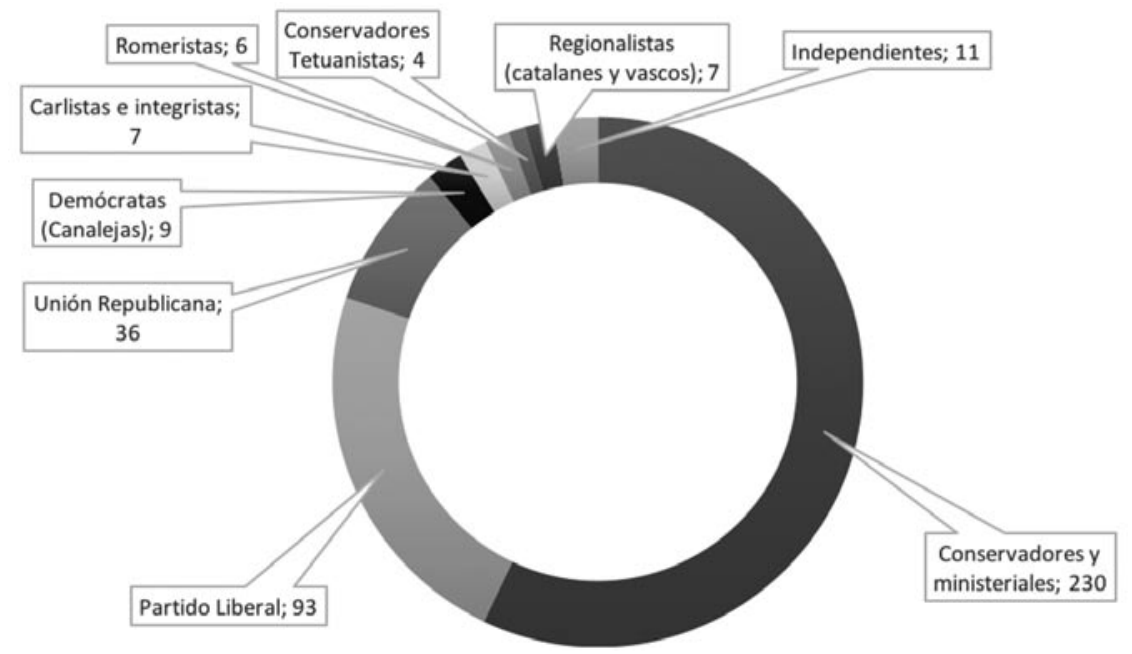

Figura 1

Distribución de escaños en las elecciones a Cortes de 1903

Fuente: Miguel Martínez Cuadrado, Elecciones y partidos políticos de España (18681931), Taurus, Madrid, 1969.

58 Joan B. Culla, El republicanisme lerrouxista ..., op. cit., pág. 70. 
En el caso de Madrid, la disciplina recuperada por los republicanos se tradujo en una victoria sin fisuras ${ }^{59}$. La prensa conservadora la definió como el premio al olvido de sus diferencias doctrinarias, pero la restó valor aludiendo al absentismo de más de la mitad de los electores, que asociaban con masas neutras «amigas de la quietud» y a la debilidad de la candidatura monárquica ${ }^{60}$. Se significaron discordancias importantes entre las dos listas, destacándose el carácter decisivo que había tenido la inclusión en la republicana de Constantino Rodríguez. Siendo este presidente del Círculo de la Unión Mercantil, habría ejercido una poderosa influencia sobre los comerciantes de los barrios centrales que solían votar en clave ministerial. Sin ir más lejos, estuvo en actos importantes para la clase mercantil celebrados en los días previos a la votación, como el mitin de la Sociedad General de Dependientes de Comercio para reivindicar el respeto del descanso dominical. También se criticó la escasa organización presentada durante la campaña. Mientras los republicanos trabajaban incesantemente en los centros electorales, liberales y conservadores apenas concedían importancia a los comités ${ }^{61}$.
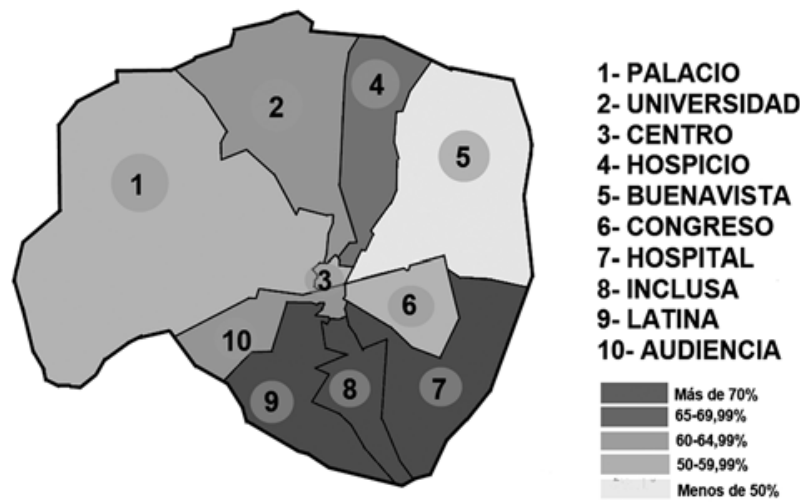

Figura 2

División administrativa de Madrid en las Elecciones a Cortes de 1903 y tendencia del voto republicano por distritos.

59 Javier Tusell, Sociología electoral de Madrid 1903-1931, Cuadernos para el Diálogo, Madrid, 1969.

${ }^{60}$ El Imparcial, 27 de abril de 1903 y ABC, 30 de abril de 1903.

${ }^{61}$ La Época, 27 de abril de 1903. 


\section{Tabla 1}

Resultados de las Elecciones a Cortes de 1903 en Madrid (votos por distritos)

\begin{tabular}{|c|c|c|c|c|c|c|c|c|c|c|c|c|c|c|c|c|c|c|c|c|c|c|}
\hline \multicolumn{23}{|c|}{ 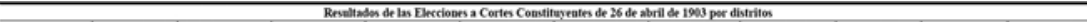 } \\
\hline \multirow{2}{*}{ Conabiator } & \multicolumn{2}{|c|}{ Palaxio } & \multicolumn{2}{|c|}{ Uwivenided } & \multicolumn{2}{|c|}{ Centro } & \multicolumn{2}{|c|}{ Bospicio } & \multicolumn{2}{|c|}{ Bonanies } & \multicolumn{2}{|c|}{ Cospew } & \multicolumn{2}{|c|}{ Horpias } & \multicolumn{2}{|c|}{ hachas } & \multicolumn{2}{|c|}{ Lenat } & \multicolumn{2}{|c|}{ Auterexis } & \multicolumn{2}{|c|}{ Toest } \\
\hline & Voton & 5 & Veton & 5 & Voos & 5 & Voton & 5 & Veotax & $\%$ & Veton & $\mathbf{5}$ & Voest & $\%$ & Veton & $\%$ & Volat & 5 & Voton & 5 & Votos & $\%$ \\
\hline $\begin{array}{l}\text { Coustution } \\
\text { Rothipere (UR) }\end{array}$ & 2.504 & 0.04 & 3.488 & 6190 & 1.385 & 5788 & 30017 & 6409 & 3.263 & 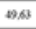 & 1858 & 52.86 & 2.39 & 79.67 & 3913 & 76.20 & 3232 & 71.05 & 2.148 & 61.14 & 28.104 & 61,45 \\
\hline Axinto of & 2270 & 44,45 & 3,439 & 61,74 & 1.282 & 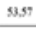 & 2962 & 6254 & 3.23 & 5.18 & 1886 & 50.80 & 3316 & 7057 & 3876 & 75 & 2123 & 6865 & 2.155 & 61.34 & 27.59 & 60.23 \\
\hline $\begin{array}{l}\text { Mignel Mo } \\
\text { (NR) }\end{array}$ & 2.584 & 50.64 & 3.431 & 61.78 & 1.165 & ss.6s & 2904 & 61.67 & 3.143 & 5781 & 1.769 & 51.28 & 2396 & 90.14 & 3913 & 78.72 & $310 \%$ & 68.44 & 2064 & 59.32 & n998 & 59.93 \\
\hline $\begin{array}{c}\begin{array}{c}\text { Marnel del Lumo } \\
(\mathrm{dx})\end{array} \\
\end{array}$ & 2.460 & 48.18 & 3.433 & 61.81 & 1.264 & 5282 & 2918 & 6197 & 3.25 & 2007 & 1833 & 52.13 & 3.31 & 70,59 & 3900 & 75.16 & 3265 & $n, n$ & 2004 & 58,47 & n.SS & 6056 \\
\hline $\begin{array}{c}\text { Neolis } \\
\text { Eathianez (UR) }\end{array}$ & 2321 & 45,46 & 3,440 & 6194 & 1.245 & 5207 & 2938 & 6239 & 3.192 & 48.55 & 1814 & 52.58 & 334 & 71.38 & 3.882 & 75.12 & $32 n$ & 7191 & 2.62 & 61.54 & 27.520 & 60.2 \\
\hline 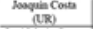 & 2351 & 46.04 & 3.455 & 6293 & 1.34 & 56.16 & 3.116 & 66.17 & 3.365 & 51.69 & 1.993 & 54,87 & 3.393 & 72.21 & 3992 & 75.31 & 3.250 & 72.30 & 2224 & 63.31 & 28.362 & 62.04 \\
\hline 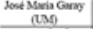 & 2986 & 88.48 & 1.765 & 31,8 & 860 & 3594 & Lass & 31,75 & 3,008 & 46.06 & 1661 & 48.14 & 1.075 & 22.88 & 853 & 16.51 & 1.195 & 3627 & 1383 & 39.37 & 16301 & 35.65 \\
\hline $\begin{array}{l}\text { Artheop Pardo } \\
\text { (2099) }\end{array}$ & 2390 & 46.81 & 1.748 & 31,6 & 1.025 & 4283 & 1.657 & 35.19 & 2983 & 45,38 & 1644 & 47,65 & 1.098 & 23,37 & 883 & 17,90 & 1.124 & 24,7 & 1052 & 29.95 & 15.604 & 34.13 \\
\hline 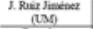 & 2.563 & 50.20 & $1.2 n$ & 32.36 & 1.056 & 4,13 & 1.725 & 36.63 & 3.18 & 47,43 & 1530 & 4406 & $1.14 !$ & 24.38 & sss & 16.5 & 1.058 & 2394 & 1.49 & 41.25 & 16313 & 35.6s \\
\hline $\begin{array}{l}\text { Framkise } \\
\text { Getienez (UMe) }\end{array}$ & 2362 & 46.26 & 1.746 & 31.44 & 1.095 & 45,76 & 1371 & 29.11 & 2.966 & 45.12 & 1634 & 47,36 & 1.053 & 22.41 & 852 & 16.49 & 1.12 & 24.62 & 1047 & 2980 & 15255 & 33.37 \\
\hline $\begin{array}{l}\text { Lonk Rivera } \\
\text { (139) }\end{array}$ & 2612 & 51.16 & 1.735 & 31.24 & 964 & 20.28 & 1.429 & 30.35 & 2993 & 45,22 & 1229 & 3562 & 1.048 & 22.30 & 947 & 18.32 & 1055 & 22.19 & 1065 & 30.32 & 15.057 & 3294 \\
\hline $\begin{array}{c}\text { Jwa Coneber } \\
\text { (23) }\end{array}$ & 2008 & 41.09 & 1.724 & 31.04 & 983 & 41.06 & 1358 & 28.84 & 2.892 & 439 & 1966 & 37.86 & 1006 & 22.90 & 89 & 17,36 & 1.061 & 22,32 & 1.024 & $\$ A 3$ & 14.429 & 31.56 \\
\hline $\begin{array}{c}\text { Prtbo lalewin } \\
\text { (PSOE) }\end{array}$ & 201 & 3,94 & 246 & 4,43 & 57 & 2.38 & 242 & 5.14 & 200 & 3,18 & 80 & 2.32 & 198 & 4.21 & 307 & 594 & 212 & 466 & 124 & 3.93 & 1.876 & 4.10 \\
\hline $\begin{array}{c}\text { Jaime Vera } \\
\text { (PSOE) }\end{array}$ & 170 & 3.33 & 218 & 293 & 42 & 1,96 & 217 & 461 & 187 & 2.84 & 72 & 200 & 159 & 402 & $2 \mathrm{s3}$ & sas & 218 & $4 \%$ & 97 & 2.76 & 1603 & $3 \times 0$ \\
\hline $\begin{array}{l}\text { Norterto Arcas } \\
\text { (ND) }\end{array}$ & 20 & 0.39 & 44 & $0 . \%$ & 93 & 3.90 & 31 & ass & 78 & 1.19 & 63 & 1.83 & 150 & 219 & 24 & o.s & 20 & 0.4 & 26 & 0.4 & 509 & 1.20 \\
\hline$\infty$ & 3 & 0.06 & 7 & 0.1 & 28 & 1.17 & 13 & 0.28 & 23 & 0.35 & 4 & 0.12 & & 17 & 17 & 0.33 & 5 & 0.11 & 10 & 28 & 1118 & 236 \\
\hline En blasso & 3 & a. & 4 & 0.07 & 4 & 0.17 & 2 & 0.04 & 6 & 0,09 & 0 & 0 & 5 & a.11 & 0 & 0 & 1 & 0.02 & 7 & 0.20 & 32 & 0.07 \\
\hline Total & 5.106 & 7,12 & 5854 & 40.13 & 2.93 & 4,22 & 4.709 & 3667 & 6.574 & 40.86 & 3.450 & sa.r1 & $4.6 n$ & 45 & s.16s & 4S.15 & 4.46 & 42.28 & 3513 & 57,41 & 45.715 & 100 \\
\hline
\end{tabular}

Leyenda: UR (Unión Republicana), UM (Unión Monárquica), PSOE (Partido Socialista Obrero Español) e IND (candidato independiente). En negrita y sombreado gris, candidatos electos. Fuente: AVS, 14-273-43, 14-274 y 14-275-1.

El escrutinio reflejó una monopolización del voto en torno a las dos formas de gobierno, lo que explica el nulo protagonismo de los socialistas. El PSOE se encontraba en una fase de paulatino ascenso, evidente también en Madrid como reflejaba la experiencia de los comicios municipales de 1901, en los que sólo un pucherazo evitó que Pablo Iglesias se hiciera con un acta de concejal. Los socialistas acudían prestos a cada batalla electoral empujados por el afán de mejorar las condiciones de vida de las clases populares, pero sin apartarse de la línea ultraclasista defendida por su líder ${ }^{62}$. En el Congreso Socialista de Gijón (septiembre de 1902) se descartó la posibilidad de un acercamiento con los republicanos, a pesar de que no faltaron voces que apuntaban hacia esta salida. Algunos miembros de la Agrupación Socialista Madrileña acudieron a la Asamblea

62 Santiago Castillo, Historia del socialismo español. Tomo 1 (1870-1909), Conjunto Editorial S.A. Barcelona, 1989 y Santos Juliá, Los socialistas en la política española. 1879-1982, Taurus, Madrid, 1997. 
Republicana del 25 de marzo, planteando, quizás ya entonces, una coalición republicano-socialista siguiendo lo estipulado en el Congreso de Madrid de $1899^{63}$. Sin embargo, Iglesias nunca se mostró abierto a una inteligencia electoral y entendió que la conducta del PSOE debía ser la misma de siempre: agitar la opinión obrera y hacer un recuento de sus huestes en Madrid $^{64}$.

Resulta fundamental ejercer un análisis microanalítico de los resultados para desentrañar las diferencias que existieron en el comportamiento electoral de los diez distritos. El caso de Palacio es muy significativo. La candidatura monárquica alcanzó un $58,48 \%$ de los votos emitidos, pero su victoria se fraguó en secciones donde predominaba el funcionariado palatino. Los republicanos esperaban la derrota, pero llamaban la atención los buenos resultados cosechados en comparación con otras citas. Sus bases sociales se localizaban en secciones con mayor presencia de jornaleros, trabajadores manuales y comerciantes como la $7 .^{\mathrm{a}}$ y $1 \mathrm{a} 8 .^{\mathrm{a}}$, donde aparecían la mayor parte de las calles que formaban parte del barrio de Álamo; y las que seguían a aquella hasta la 12. ${ }^{a}$, donde se comprendían parte de los barrios de Amaniel, Conde de Toreno y Quiñones. Fue allí donde los candidatos de UR alcanzaron entre un 60-70\% de los votos emitidos.

El estudio de la 7. a sección (calles de Antonio Grilo, Federico Balart, Flor Baja, Isabel la Católica, Parada y travesía de la Parada) a partir de los datos del Padrón de 1905 permite comprender las características socioeconómicas de las zonas más proclives al voto republicano en este distrito. Los alquileres de las viviendas eran muy bajos en comparación con los barrios de los alrededores (en torno a 50 pesetas mensuales) y la mitad de los cabezas de familia eran trabajadores de la producción, pero con un protagonismo evidente de jornaleros que ofrecían unos exiguos ingresos medios de 2,61 pesetas diarias. El resto de cabezas de familia se adscribía al sector servicios tradicional y tan sólo un 5\% se vinculaba a centros oficiales estatales o municipales, lo que reducía las posibilidades de la can-

${ }^{63}$ En ese congreso se determinó que el PSOE podría cooperar con los partidos burgueses avanzados cuando los principios democráticos corrieran peligro de desaparecer. En: Juan José Morato, El Partido Socialista Obrero, Biblioteca Nueva, Madrid, 1918, pág. 130. Asimismo, véase la asistencia de algunos miembros de la Agrupación Socialista Madrileña a la Asamblea Republicana del 25 de marzo de 1903 en: Joan Serrallonga, Pablo Iglesias. Socialista, obrero y español, Edhasa, Barcelona, 2007, pág. 453.

${ }^{64}$ El Socialista, 17 de abril de 1903. 
didatura ministerial ${ }^{65}$. Las diferencias eran insalvables con respecto a la 3. a sección. Los empleados de las Reales Caballerizas votaron en masa a la candidatura dinástica. Pese a todo, no habría que descartar la posibilidad del fraude electoral en este punto. Algunos periódicos señalaron que el presidente de la mesa electoral, Francisco Coll, despejó el local donde se celebraba la votación y se quedó sólo, sin duda alguna para disponer de unas actas en blanco posteriormente rellenadas al alza en favor de los candidatos monárquicos ${ }^{66}$.

Las características sociológicas de Palacio justificaron una intensa vigilancia de los colegios por parte de los republicanos. Las mayores preocupaciones se encontraban en la 1. ${ }^{a}$ sección, que comprendía el Cuartel de Alabarderos. Los interventores levantaron una protesta en el acta por la que juzgaban incumplidas las normas de la circular de la Junta Central del Censo Electoral del 14 de abril. En aquella sección ejercieron su voto un significativo número de alabarderos que alegaron su condición de oficiales. Aunque el candidato republicano Morayta acudió al Consejo de Estado para denunciar esa situación, Joaquín Álvarez Buylla, presidente de la sección, esquivó la reclamación señalando que no había recibido resolución de la Junta Central del Censo, no creyéndose «con atribuciones para negarles la emisión del sufragio ${ }^{67}$. Los monárquicos alcanzaron aquí uno de los porcentajes de voto más altos del distrito: Garay y Rowart apareció en dos de cada tres papeletas depositadas en las urnas. Mayor éxito tuvieron los candidatos de UR en el resto de secciones. Los republicanos presentes en las mesas y los estudiantes consiguieron que los presidentes emitieran todas las certificaciones estipuladas en la circular de la Junta Central del Censo. La actividad fue especialmente eficiente en secciones como la 22. ${ }^{\text {a }}$, que comprendía las calles más cercanas a la Ribera del Manzanares. Los interventores evitaron allí el funcionamiento de rondas de votantes obreros del ramo de alcantarillado del Ayuntamiento de Madrid $^{68}$. Sin menoscabar el apoyo que los republicanos podían lograr en los barrios más populares parece evidente que estas tareas fueron decisivas para equilibrar la balanza con respecto a unos monárquicos que siempre obtenían mayorías aplastantes en este distrito.

\footnotetext{
65 Padrón de Habitantes de 1905, AVM, Estadística.

${ }^{66}$ La Correspondencia de España, 27 de abril de 1903.

67 AVS, 14-275-1.

${ }^{68}$ El Imparcial, 27 de abril de 1903.
} 


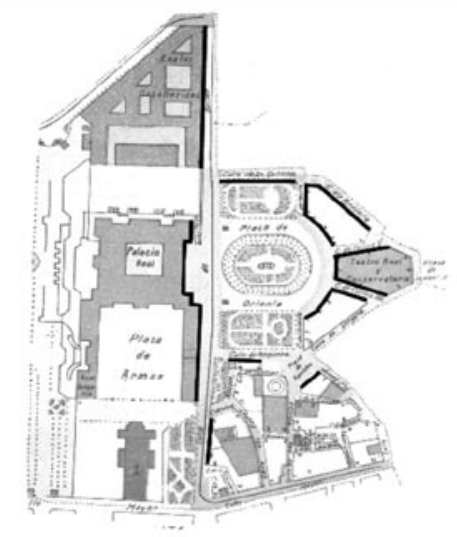

SECCIÓN 3 (PALACIO)

Número de electores: 488

Número de votantes: 343

Votos monárquicos: 319

Votos republicanos: $\mathbf{5 2}$

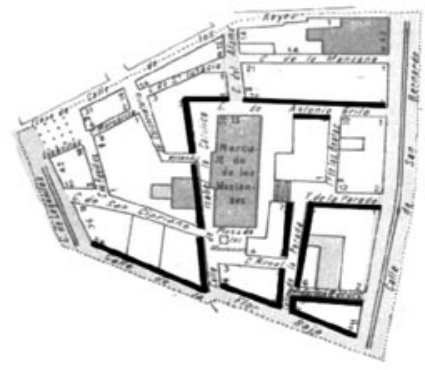

SECCIÓN 7 (PALACIO)

Número de electores: 490

Número de votantes: 197

Votos monárquicos: 79

Votos republicanos: 120

Figura 3

Resultados electorales en las secciones 3 y 7 del distrito de Palacio

Leyenda: Sobre línea negra, calles que forman parte de las secciones indicadas. Elaboración propia sobre el plano de: Álvaro González Iribas, Guía Práctica de Madrid, R.Velasco, Madrid, 1906 a partir de los datos electorales procedentes de AVS, 14-275-1. El mismo documento ha sido utilizado en mapas sucesivos.

Buenavista y Congreso inspiraban gran confianza a la candidatura monárquica, pero los republicanos coparon en ambos distritos las seis primeras posiciones en número de votos. En Buenavista, el apoyo que recibieron los segundos en secciones como la 15. (primeros números de la calle de Alcalá, parte de la de Almagro, Juan Bravo y Recoletos) o en la 13. ${ }^{\mathrm{a}}$, donde votaba la flor y nata de la sociedad empadronada en el Paseo de la Castellana, fue mínimo. La situación cambiaba en ciertos puntos del casco antiguo definidos por una mayor mezcolanza social y en las secciones de las afueras del Ensanche. Los elevados porcentajes de voto republicano en Plaza de Toros, Guindalera o Prosperidad mostraban la eficacia 
de las tareas propagandísticas desarrolladas en los barrios menos desarrollados desde un punto de vista político. La situación también parecía favorable para los monárquicos en Congreso, donde se empadronaba un importante número de aristócratas, grandes propietarios y empleados. Los monárquicos obtuvieron un mayor respaldo en las secciones $13 .^{\mathrm{a}}$ y $14 .^{\mathrm{a}}$, colindantes con el Retiro, mientras que el apoyo de los republicanos fue más notorio en la 4. a, que incluía calles secundarias cercanas a la Puerta del Sol definidas por una mayor concentración de artesanos y pequeños comerciantes. No obstante, los votos de ambas candidaturas no se circunscribían a una disyuntiva social tan clara como en Palacio o Buenavista. La atracción creada por UR sobre las masas neutras resulta una hipótesis que cobraría validez viendo los resultados de secciones como la $6 .^{\mathrm{a}}$, que integraba buena parte de las calles situadas en Floridablanca, uno de los barrios con alquileres más elevados del centro. El mayor protagonismo de profesionales liberales vino acompañado de votaciones sustanciales para las figuras intelectuales de UR como Costa y Octavio Picón.
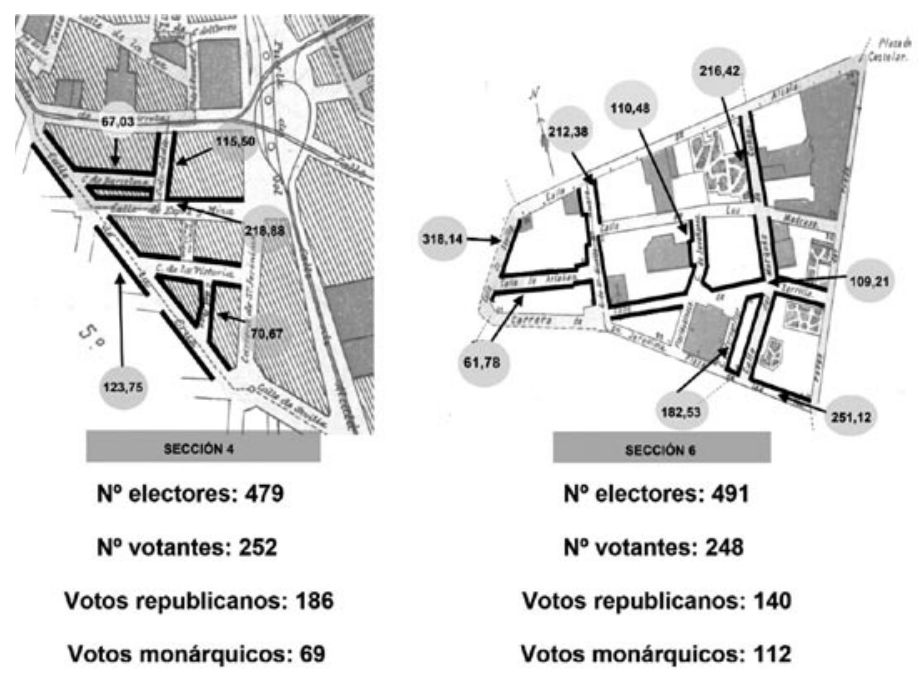

Figura 4

Alquileres y resultados electorales en las secciones 4 y 6 de Congreso

Fuente: Padrón de Habitantes de 1905 y actas electorales de Congreso en: AVS, 14-273-43. 


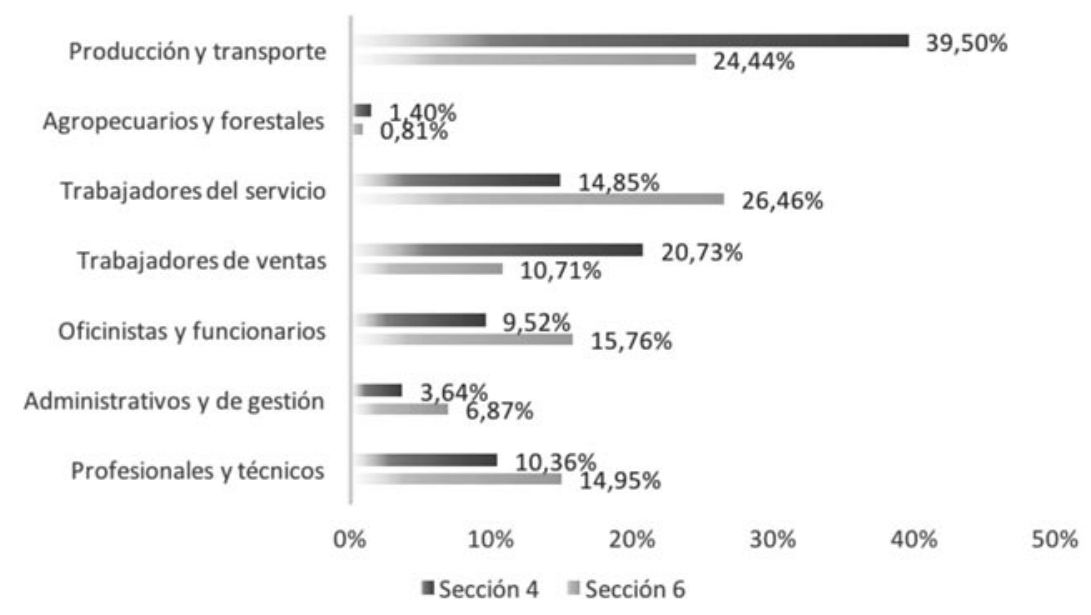

Figura 5

Clasificación profesional de los empadronados en las secciones 4 y 6 de Congreso

Fuente: Padrón de Habitantes, 1905.

La valoración de los resultados electorales en las zonas acomodadas se cierra con el distrito de Centro. A pesar de que la nota predominante durante la votación fue la tranquilidad, las comisiones estudiantiles y los interventores republicanos mostraron gran actividad en las mesas. Los primeros, ejerciendo presión sobre los presidentes de ciertas secciones para que suscribieran certificaciones de las actas de escrutinio. Los segundos, aplicando las instrucciones de los notarios al servicio de la UR. Cuando comenzaron sus trabajos electorales en la sección 7. (calle del Arenal y alrededores) descubrieron un procedimiento utilizado por los monárquicos para favorecer, en connivencia con el presidente de la mesa, la participación de electores con nombres falsos. Consistía en marcar a aquellos con un sello azul en la palma de la mano derecha, que veía el presidente de la mesa cuando aquellos le entregaban las papeletas. Advertidos por correligionarios y estudiantes de esa estrategia, los interventores republicanos echaron del colegio a quienes acudían con ese distintivo ${ }^{69}$.

69 El País, 27 de abril de 1903. 
La victoria republicana fue menos nítida que en el resto de distritos, pero, aún y con todo, sorprendente para los monárquicos. La prensa hablaba días antes de la votación del carácter favorable que esta zona presentaba para la candidatura adicta por el elevado número de funcionarios, empleados del Palacio Real y familias aristocráticas que poblaban sus calles. Sin embargo, en la mayoría de las secciones o bien obtuvieron más votos los republicanos, o bien quedaron a escasa distancia de los monárquicos. Constantino Rodríguez fue el más apoyado. Que encabezara la lista republicana evidenciaba la importancia que había tenido el voto de comerciantes e industriales.

El objetivo de los republicanos de Centro fue atraer a los comerciantes de la zona para contrarrestar la superioridad de los funcionarios. Para conseguirlo, no había mejor opción que la de aquel candidato formado en la Institución Libre de Enseñanza. Tras convertirse en profesor de comercio en 1885 se lanzó a la política con el objetivo de ingresar en el Ayuntamiento de Madrid. Una vez lo consiguió, se ganó la simpatía de todo el vecindario. Defendió a pequeños comerciantes cuando el consistorio planteó subidas indiscriminadas de impuestos y formó parte de la Comisión de Consumos, una de las más salpicadas por escándalos de corrupción hasta entonces. Pese a todo, no dejó de lado su protagonismo en el Círculo de la Unión Mercantil, en el Centro de Instrucción Comercial y en la Mutua Mercantil e Industrial, que él mismo creó en 1903 para proteger los intereses de los de su clase ${ }^{70}$.

Cuando Constantino Rodríguez se postuló como candidato recibió un apoyo mayoritario. Sus porcentajes de voto más altos podían ser distinguidos en función de las características socioeconómicas de cada zona. En secciones como la 7. a, que incluía parte de la calle Mayor, las calles de Bordadores y Coloreros y la plaza de Herradores, fue votado por el $60,87 \%$ de unos electores que en una quinta parte de los casos analizados estaban insertos en el sector comercial. La contribución industrial que pagaban los dueños de los establecimientos era muy elevada (722,62 pesetas anuales de media), lo que demostraba que los republicanos contaban con el apoyo de los comerciantes más prósperos de este espacio. Pero la candidatura republicana también atraía a comerciantes de recursos más exiguos, a propietarios de pequeños talleres e incluso aquellos que tenían puestos de venta en el Mercado del Carmen em-

${ }^{70}$ Los datos de Constantino Rodríguez en: El País, 20 de agosto de 1916. 
padronados en las calles de los alrededores en la 2. ${ }^{a}$ sección (Chinchilla, Mesonero Romanos y Salud). La situación era similar en la sección $11 .^{\text {a }}$, que integraba parte de las calles condenadas a la desaparición tras la aprobación del proyecto de Gran Vía en su tercer tramo (Tudescos, Silva, Callejón del Perro y Callejón de Tudescos). El alquiler medio bajaba hasta las 58,59 pesetas, lo que abría posibilidades al asentamiento de trabajadores no cualificados. La proporción de comerciantes era más baja que en las secciones anteriores y su categoría mucho más modesta. La contribución industrial que abonaban descendía hasta 217,84 pesetas de media, siendo las tabernas, los ultramarinos y las carbonerías las grandes protagonistas.

Jornaleros (sobre total del mercado laboral)
Producción y transporte
Trabajadores del servicio
Trabajadores de ventas
Oficinistas y funcionarios
Administrativos y de gestión
Profesionales y técnicos

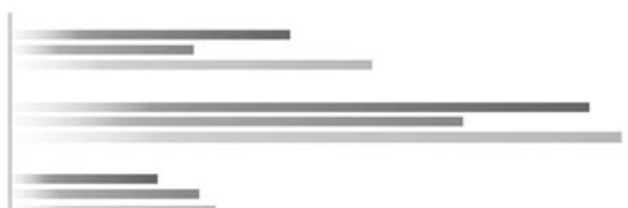

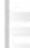
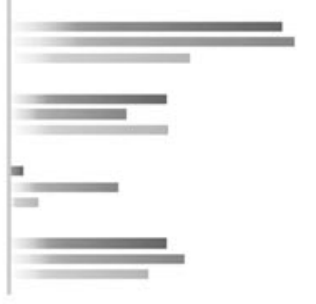

10

20

$2^{30}$

40

50

aSección 2 asección 7 Sección 11

\section{Figura 6}

Clasificación profesional de los empadronados en las secciones 2, 7 y 11 de Centro

Fuente: Padrón de Habitantes de 1905. 


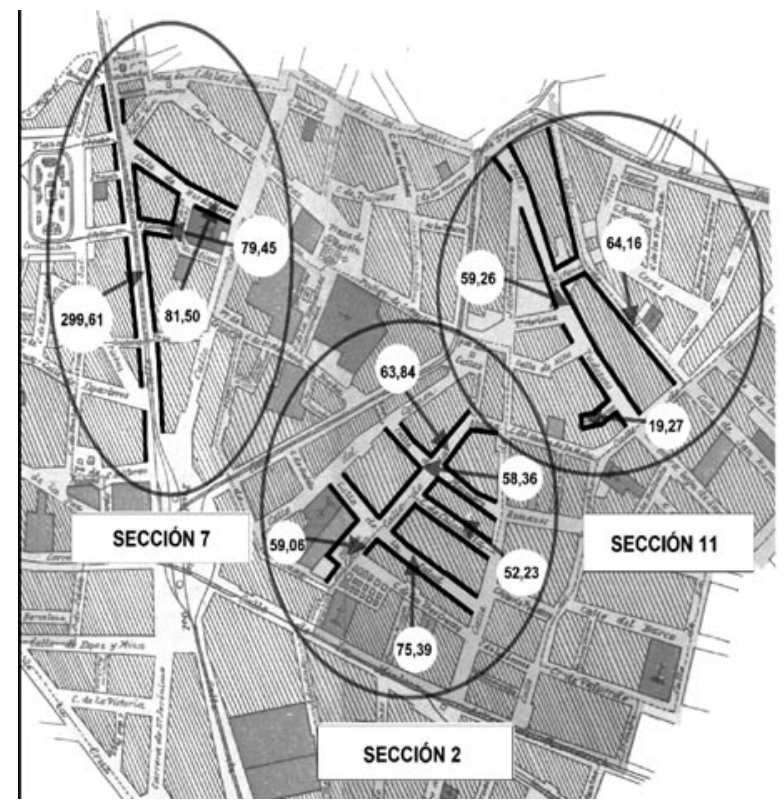

SECCIÓN 2

NN electores: 495

$\mathrm{N}^{\circ}$ votantes: 242

Votos republicanos: 165

Votos monárquicos: 76

SECCIÓN 7

No electores: 497

No votantes: 207

Votos republicanos: 126

Votos monárquicos: 90

SECCIÓN 11

No electores: 481

$N^{\circ}$ votantes: 191

Votos republicanos: 178

Votos monárquicos: 160

\section{Figura 7}

Alquileres y resultados electorales en las secciones 2, 7 y 11 del distrito de Centro

Fuente: Padrón de Habitantes de 1905 y actas electorales de Centro en: AVS, 14-274-1.

Las diferencias entre republicanos y monárquicos crecían significativamente en el resto de distritos. En Audiencia, los interventores republicanos y socialistas trabajaron conjuntamente para evitar irregularidades en las secciones en las que tenían participación en las mesas. Con el apoyo de los electores evitaron que se produjeran abusos en la 7. a sección, que englobaba la calle y plaza del Duque de Alba, parte de la calle de Toledo y la calle de los Estudios. En ella se presentó una nueva negativa del presidente de la mesa a dar certificaciones de un escrutinio favorable a los republicanos. Se expulsó a los electores del colegio y se produjo el cierre del mismo, si bien las posteriores presiones desarrolladas por los correligionarios de UR evitaron la manipulación de los resultados ${ }^{71}$. Los por-

71 El Imparcial, 27 de abril de 1903. 
centajes de votos republicanos más elevados procedieron de la $2 .^{\mathrm{a}}, 3$. $^{\mathrm{a}}$ y 9. ${ }^{\text {a }}$ sección, que incluían las calles de los alrededores de la plaza Mayor, parte de la calle de Toledo y otras vías aledañas. La naturaleza mercantil y artesanal de esta zona llevaría a lanzar la hipótesis de que un número importante de pequeños comerciantes y trabajadores manuales cualificados decidieron votar la candidatura republicana en masa, atendiendo a unos intereses defendidos por Constantino Rodríguez durante la campaña. De igual manera, no habría que perder de vista que buena parte de los trabajos de la campaña republicana en este distrito se habían desarrollado en la Tertulia Progresista, que había servido para resolver las reclamaciones de los vecinos relativas al censo.

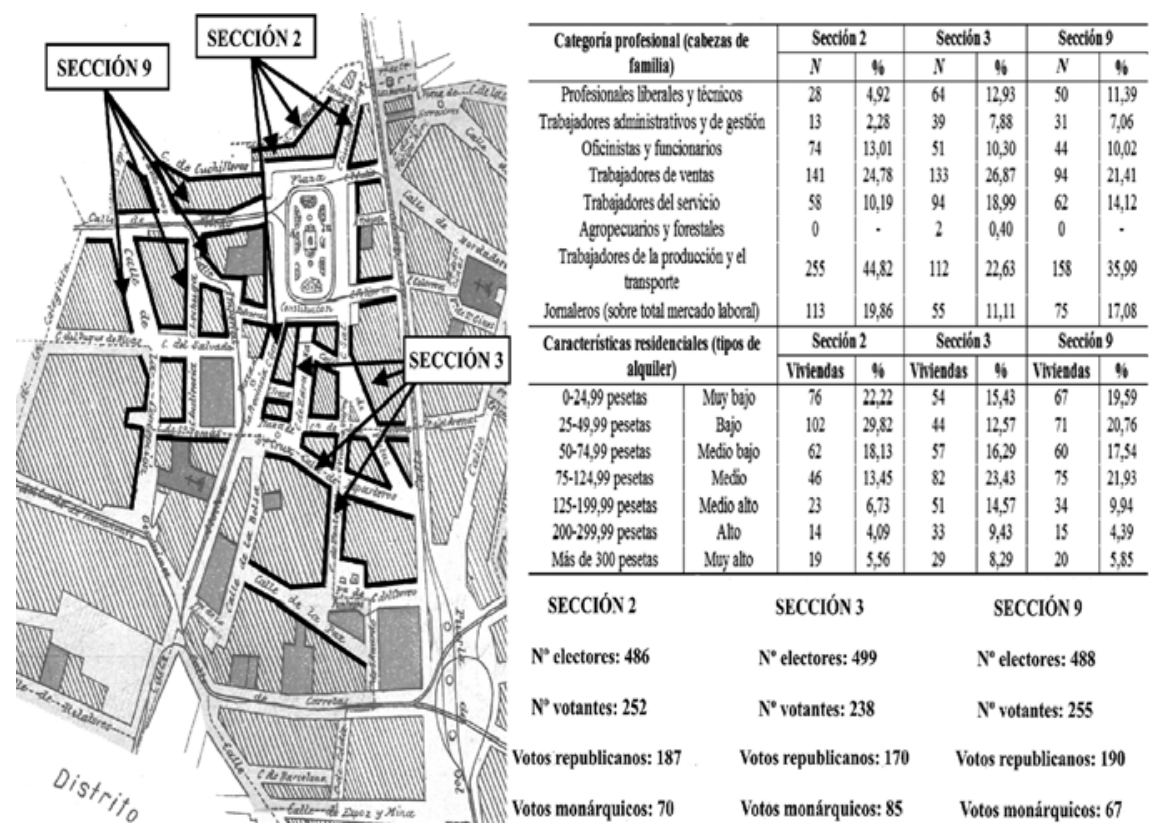

Figura 8

Características socioeconómicas de las secciones 2, 3 y 9 del distrito de Audiencia

Leyenda: A la izquierda, calles comprendidas en las secciones 2, 3 y 9 de Audiencia. A la derecha, características socioprofesionales y alquileres de las zonas señaladas según los datos del Padrón de Habitantes de 1905 y resultados electorales (AVS, 14-273-43). 


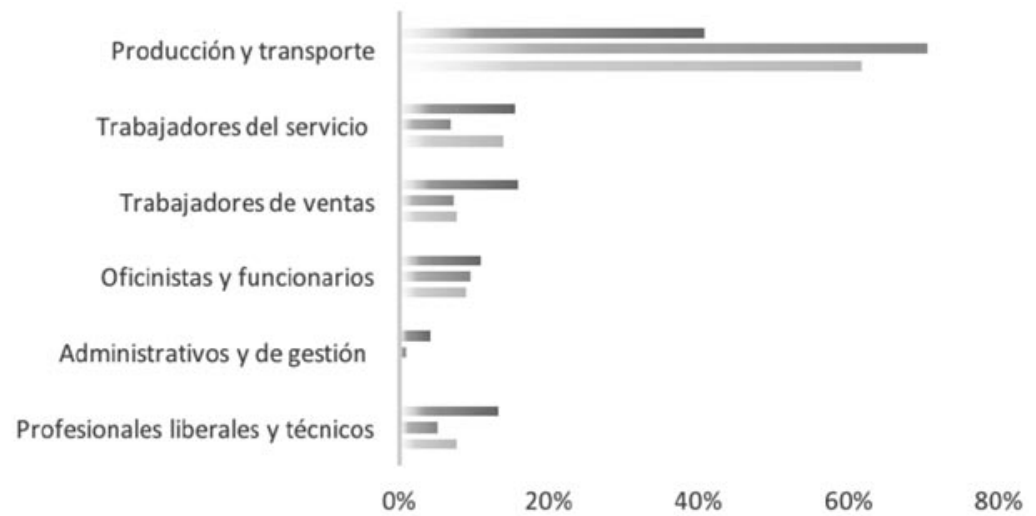

Mección 2 \Sección 17 "Sección 19

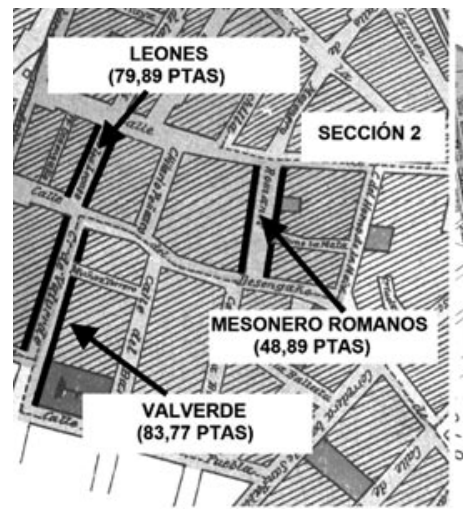

SECCIÓN 2

$\mathrm{N}^{\circ}$ electores: 475

$\mathbf{N}^{\circ}$ votantes: 200

Votos republicanos: 126

Votos monárquicos: 75

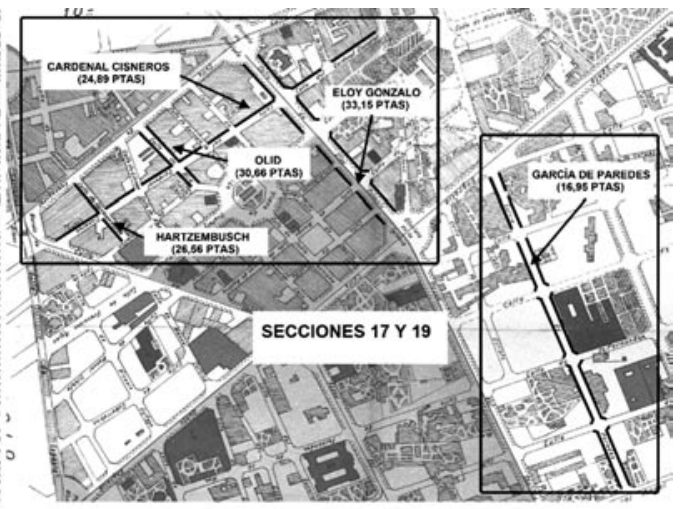

SECCIÓN 17

$\mathrm{N}^{\circ}$ electores: 499

$N^{\circ}$ votantes: 173

Votos republicanos: 156

Votos monárquicos: 36

\section{SECCIÓN 19}

$\mathrm{N}^{\circ}$ electores: $\mathbf{5 0 0}$

$\mathrm{N}^{\circ}$ votantes: 199

Votos republicanos: 124

Votos monárquicos: $\mathbf{3 1}$

Figuras 9 y 10

Características socioeconómicas y resultados electorales de las secciones 2, 17 y 19 de Hospicio

Fuente: Padrón de Habitantes de 1905 y actas electorales de Hospicio (AVS, 14-274-1). 
Hospicio y Universidad ofrecieron resultados muy similares a los de Audiencia. En el primer distrito, las papeletas republicanas colmaron las urnas de los colegios del Ensanche. El contraste con la propaganda desarrollada por los monárquicos fue más que evidente. En los barrios del Ensanche podían encontrarse secciones en las que aquellos ni siquiera contaban con interventores, lo que permitió que se pudiera negar el voto a los guardias de seguridad sin demasiadas objeciones por parte de los presidentes. Tomando como casos de estudio las secciones 17..$^{\mathrm{a}}$ y $19 .^{\mathrm{a}}$ se observa un porcentaje de voto monárquico inferior a un $20 \%$ frente al $75-80 \%$ que presentaba el candidato de UR más votado. Los monárquicos incrementaron su apoyo en algunas secciones del casco antiguo, si bien sobrepasando en pocas ocasiones el $50 \%$ de votos. El periodista Modesto Moyrón, quien había sido director de $E l$ Nuevo Combate además de interventor en este distrito y candidato en las elecciones municipales de 1901, fue una figura clave durante la jornada electoral. Recorrió todos los colegios defendiendo a los interventores y llevando notarios a las secciones en que los presidentes se negaban a darles asiento.

En Universidad la victoria republicana fue igualmente contundente. 27 de las 28 secciones dieron su apoyo a la candidatura. Al igual que en Hospicio, las diferencias entre las secciones del casco antiguo y las emplazadas en el Ensanche y en el Extrarradio eran evidentes. Los monárquicos podían aspirar a porcentajes de voto cercanos al $40 \%$ en las primeras, pero sus posibilidades eran mínimas en las secciones que integraban calles situadas en las afueras del Ensanche Norte o en el Extrarradio. La ausencia de una orientación política clara en aquellos espacios en sus primeros años de desarrollo tras la formalización del plan del Ensanche fue aprovechada por los republicanos cuando el sufragio se convirtió en un derecho ciudadano. La movilización que desarrollaron sobre los vecinos de esas zonas generó un poso de apoyo al movimiento que se tradujo en victorias incontestables en diferentes citas electorales ${ }^{72}$. En cuanto a las secciones situadas en ciertas barriadas del Extrarradio, como la de Bellas Vistas, la confianza en la candidatura adicta también era mínima, si bien en este caso jugaban una influencia más determinante los trabajos de movilización del voto desarrollados

72 Rubén Pallol, Una ciudad sin límites. Transformación urbana, cambio social y despertar político en Madrid, 1860-1931, Catarata, Madrid, 2013. 
por los republicanos los días previos a la votación. Los propios candidatos se habían personado en los mítines celebrados en estas zonas para captar el apoyo de los jornaleros, albañiles y obreros municipales allí empadronados. Dicho esto, no debe extrañar lo que ocurrió en la sección 23. ${ }^{a}$. Quienes acudieron durante aquella jornada a votar al colegio instalado en el aula 6 de la Universidad Central eran mayoritariamente jornaleros que no solían indicar especialización al rellenar las casillas del Padrón. Tampoco sorprende el escenario dibujado en la sección $28 .^{\text {a }}$, que comprendía algunas calles sin urbanizar de Bellas Vistas. Sus vecinos correspondieron el acercamiento de los candidatos en los mítines de la campaña dejando ocho de cada diez papeletas favorables para la causa republicana.

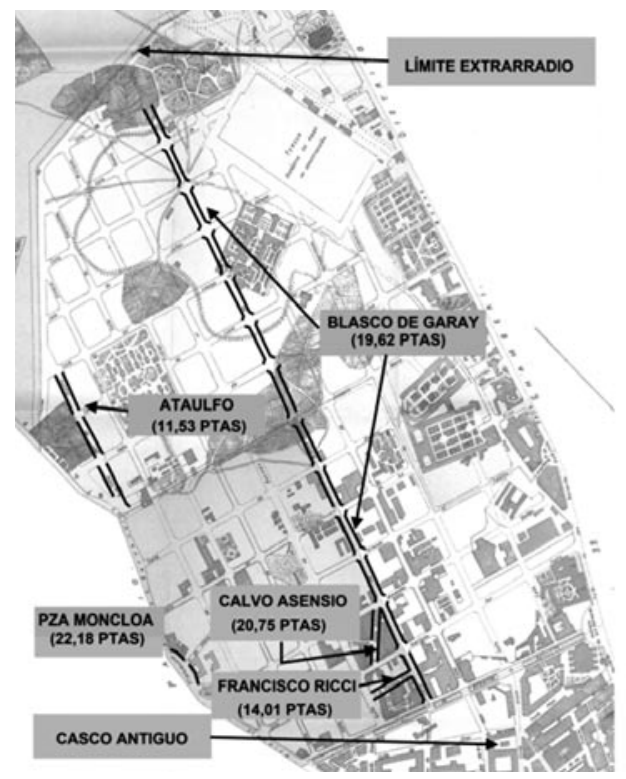

SECCIÓN 23 (UNIVERSIDAD)

$\mathbf{N}^{\circ}$ electores: $\mathbf{5 0 0}$

$\mathrm{N}^{\circ}$ votantes: 196

Votos republicanos: 162

Votos monárquicos: 32

Votos socialistas: 5

Figura 11

Características residenciales y resultados de la sección 23 del distrito de Universidad Fuente: Actas electorales de Universidad en: AVS, 14-274-1. 
Una de las notas más destacadas de la jornada fue el entusiasmo republicano vivido en Inclusa, Hospital y Latina. El primer distrito despertaba gran atención, especialmente en secciones compuestas por las calles donde se habían producido los altercados de comienzos de abril. El descalabro de los partidos dinásticos podía sentirse en los alrededores de los colegios desde primera hora de la mañana. En el que se situaba en el Matadero de Cerdos, donde correspondía votar a los electores de las secciones $4 .^{\text {a }}$ y $5 .^{\text {a }}$ (plaza y travesía del Rastro, calles de Amazonas, Peñón y Santa Ana) se formaron colas de cien personas, candidatura republicana en mano, mucho antes de abrirse el turno para votar. Los electores seguían así las recomendaciones que habían escuchado en el mitin celebrado en las Escuelas Pías de San Fernando dos días antes ${ }^{73}$. Calles como Embajadores o Mesón de Paredes se convirtieron en regueros de obreros y pequeños industriales que acudían a los colegios haciendo propaganda republicana durante su trayecto. Los vecinos de estos barrios tenían presente lo acontecido semanas atrás e incluso de los balcones de las casas colgaban carteles con los nombres de los candidatos republicanos. Cualquier intento de manipulación era desbaratado por los correligionarios del partido y las comisiones estudiantiles y de nada sirvió que aparecieran empleados de consumos repartiendo candidaturas monárquicas o que se registraran intentos de compra de votos en calles como Huerta del Bayo, Rodas, Amparo y Mesón de Paredes. La descripción del distrito tras conocerse el escrutinio se asemeja bastante a la de un paisaje festivo. El centro electoral de la calle de la Encomienda quedó iluminado al atardecer y numerosos vecinos recorrieron los barrios entonando La Marsellesa ${ }^{74}$.

En Hospital destacaron la persecución del matute electoral (cerrándose casas reconvertidas en centros para la recepción de rondas volantes), las comisiones estudiantiles que acudían al centro electoral para ofrecer su ayuda durante la jornada, la predisposición mostrada por los notarios republicanos y el entusiasmo de los apoderados, que horas antes de iniciarse la votación acudieron a las casas de los interventores para proveerles de la documentación a utilizar en las mesas. La disciplina llegó a tal punto que, al margen de los interventores republicanos de las mesas, había otros defi-

73 El País, 25 de abril de 1903.

74 El Liberal, 27 de abril de 1903. 
nidos como extraoficiales en los colegios para cotejar los votos obtenidos por sus candidatos ${ }^{75}$.

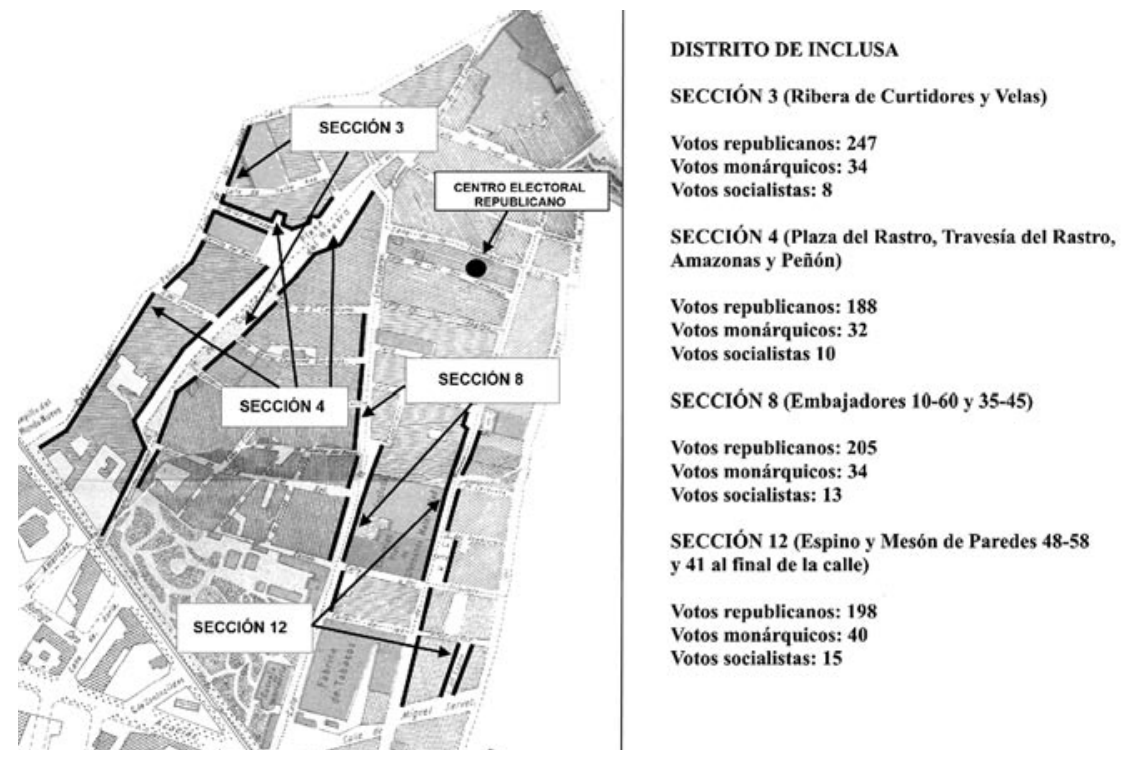

Figura 12

Resultados electorales en distintas secciones del distrito de Inclusa

Fuente: Padrón de Habitantes de 1905 y actas electorales de Inclusa en: AVS, 14-274-1.

En cuanto a Latina, la prensa volvió a significar los numerosos grupos de correligionarios situados en las puertas de los colegios vigilando la entrada de electores para impedir las votaciones falsas y las colas de obreros en las calles de Arganzuela, Humilladero y Calatrava. Republicanos y socialistas trabajaron de manera conjunta en estas zonas, encargándose los segundos de colocar a aprendices de los talleres tipográficos junto a los colegios para repartir candidaturas ${ }^{76}$. El Extrarradio volvía a

${ }^{75}$ La Correspondencia de España, 27 de abril de 1903.

76 El Heraldo de Madrid, 26 de abril de 1903. 
ofrecer diferencias abismales, especialmente la sección en la que emitían el sufragio los habitantes de las zonas no urbanizadas de la Ronda y la Carretera de Toledo y de la barriada de San Isidro. No obstante, el apoyo a los republicanos también era manifiesto en calles pertenecientes a barrios populares del casco como Calatrava y Arganzuela. Parece evidente que la acusada orientación de las clases populares y del elemento obrero de estos tres distritos hacia las filas republicanas habría que explicarla teniendo en cuenta la variable del arraigo republicano y de los altercados producidos en sus barrios a raíz de los sucesos de Salamanca. No obstante, también es posible lanzar la hipótesis de que un número importante de los votos socialistas derivados de ciertos sectores laborales en elecciones anteriores terminaron por desviarse hacia la candidatura de UR, en una actitud de colaboración informal similar a la que mostraron los interventores socialistas con los republicanos en las mesas electorales.

El júbilo republicano creció imparablemente en los días que siguieron a las elecciones. Las páginas de El País están repletas de referencias a actos de celebración del triunfo en centros y círculos republicanos diseminados por toda la capital, a mítines en los locales de la Tertulia Progresista y del Centro Federal, a manifestaciones improvisadas de obreros y estudiantes en los barrios del sur, a la organización de giras campestres para homenajear a los interventores e incluso a iniciativas que permitiesen a las comunidades migratorias afincadas en Madrid conmemorar el triunfo en sus lugares de origen, como se evidencia en la comida popular preparada para los estudiantes valencianos en los Viveros de la Villa ${ }^{77}$. El punto álgido de este entusiasmo se alcanzó con la llegada de Salmerón a Madrid. Sus declaraciones en el andén de la estación de Atocha ante la multitud allí congregada simbolizan una voluntad nacional de acción coordinada por parte de UR que, sin embargo, tardó poco tiempo en disiparse: «Madrid, Barcelona, Valencia y Zaragoza, entre otras muchas capitales de España, no quieren ser gobernadas por hombres ineptos. Bien claro lo han demostrado en la ocasión presente. Yo os traigo, republicanos de Madrid, un fuerte abrazo de vuestros hermanos de Barcelona; yo os traigo, estudiantes madrileños, el saludo entusiasta de los estudiantes catalanes ${ }^{78}$.

77 El País, 27-29 de abril de 1903.

78 El País, 30 de abril de 1903. 


\section{Conclusiones}

Las elecciones a Cortes de 1903 permitieron al gobierno lograr la mayoría, pero los resultados de las grandes ciudades tuvieron una enorme resonancia. Los republicanos demostraron que contaban con recursos suficientes para lograr una movilización política a mayor escala y sacar beneficios de un sistema electoral competitivo en las circunscripciones libres. La formación de Unión Republicana abrió las puertas a un entusiasmo reflejado en distintos escenarios a nivel nacional. En el caso de Madrid, Barcelona y Valencia, pudo advertirse en el desarrollo de una gran fuerza organizativa ejemplificada en el funcionamiento de los centros electorales y en el seguimiento de tareas propagandísticas en barrios que todavía no habían adoptado un perfil político definido. Los republicanos sacaron provecho de una frágil coyuntura nacional presentándose como abanderados del movimiento regeneracionista y líderes de una política democrática que debía desarrollarse desde ámbitos de sociabilidad amplios y renovados. Comprendieron que lo importante era la cohesión y el encuadramiento para dar forma a su andamiaje político y modernizar sus mecanismos de captación del sufragio. La actividad emprendida desde los comités de distrito, desde los círculos y desde calles y locales con los mítines fue la expresión más concluyente de un proceso que reveló varias cuestiones decisivas. Los integrantes de la Unión Republicana intensificaron sus esfuerzos para la conquista del pasivo electorado madrileño cuidando al detalle los procedimientos para la revisión del censo electoral (claves para desarticular los resortes administrativos puestos en liza por los aparatos gubernamentales), para el adoctrinamiento de sus correligionarios (decisivos para fiscalizar el comportamiento electoral en los colegios y los posteriores escrutinios) y para garantizar la correcta actuación de notarios e interventores (con nuevos instrumentos de pedagogía electoral).

El entusiasmo republicano se fortaleció con los apoyos procedentes de las asociaciones estudiantiles, agitadas por los sucesos acaecidos en Salamanca a comienzos de abril de 1903. En las calles de Madrid salieron a escena inconfundibles elementos de ritualización republicana asociados a las protestas contra el gobierno, alcanzando las tensiones su punto más álgido en los barrios del sur del casco antiguo. Estos fueron los que mostraron mayor efervescencia política durante la jornada electoral del 26 de abril de 1903 y los que apoyaron sin fisuras a la candidatura republicana. Sin embargo, Madrid era una ciudad ofrecía múltiples semblantes, fenó- 
meno que siempre había generado discordancias entre sus espacios en cuanto a tendencias del voto se refiere. Esa división se presentó también en estas elecciones, pero de una manera más atemperada que en otras citas. En líneas generales, lo único que varió fue la gradación del triunfo republicano, notable incluso en distritos que a priori no se presentaban como favorables para su causa por la composición de su vecindario.

Sin embargo, la pluralidad política de Madrid no sólo es advertible a través del análisis a nivel de distrito. Comprender los procesos influyentes en el comportamiento electoral y político de una población exige realizar aproximaciones micro-analíticas a nivel de sección electoral. La adscripción de los electores en términos de comunidad política cobra un sentido claro en relación al contexto urbano de división socio-espacial que genera el propio mercado laboral. En el interior de distritos como Centro, Audiencia, Congreso o Palacio confluían áreas con estructuras sociales distintas en las que gestaban caracteres de política local no homologables. Lo mismo se podría decir de distritos que integraban secciones en el casco antiguo, en el Ensanche y en el Extrarradio, como Universidad. Las zonas antiguas del interior solían estar mejor controladas por los partidos dinásticos del turno, por haberse establecido ya en ellas redes clientelares y elementos de sociabilidad política. Por el contrario, los espacios que habían ido emergiendo al compás del crecimiento demográfico eran virginales desde un punto de vista político, aspecto bien comprendido por los centinelas de Unión Republicana como se demostró en las jornadas previas a la votación. 